\title{
New trends in plasmonic (bio)sensing
}

\section{JORGE R. MEJÍA-SALAZAR ${ }^{1}$, SABRINA A. CAMACHO ${ }^{2}$, CARLOS J. L. CONSTANTINO ${ }^{2}$ and OSVALDO N. OLIVEIRA JUNIOR ${ }^{1}$}

\author{
${ }^{1}$ São Carlos Institute of Physics, University of São Paulo, PO Box 369, 13560-970 São Carlos, SP, Brazil \\ ${ }^{2}$ School of Technology and Applied Sciences, São Paulo State University (UNESP), Campus Presidente Prudente, 19060-900 \\ Presidente Prudente, SP, Brazil
}

Manuscript received on July 24, 2017; accepted for publication on October 4, 2017

\begin{abstract}
The strong enhancement and localization of electromagnetic field in plasmonic systems have found applications in many areas, which include sensing and biosensing. In this paper, an overview will be provided of the use of plasmonic phenomena in sensors and biosensors with emphasis on two main topics. The first is related to possible ways to enhance the performance of sensors and biosensors based on surface plasmon resonance (SPR), where examples are given of functionalized magnetic nanoparticles, magnetoplasmonic effects and use of metamaterials for SPR sensing. The other topic is focused on surface-enhanced Raman scattering (SERS) for sensing, for which uniform, flexible, and reproducible SERS substrates have been produced. With such recent developments, there is the prospect of improving sensitivity and lowering the limit of detection in order to overcome the limitations inherent in ultrasensitive detection of chemical and biological analytes, especially at single molecule levels.
\end{abstract}

Key words: Plasmonics, Biosensing, Sensing, SERS, Magnetoplasmonics, TMOKE.

\section{INTRODUCTION}

Surface plasmon resonances (SPRs) have been extensively exploited for sensing and biosensing (Nylander et al. 1982, Liedberg et al. 1983) with enormous progress in recent years both in terms of instrumentation and applications. Important challenges remain, nevertheless, including the need to enhance the sensitivity to detect low-molecular-weight biomolecules, and the search for suitable conditions for miniaturization. As for localized surface plasmon-resonances (LSPRs) in metallic nanoparticles and nanostructures made as arrayed nanoparticles, the electromagnetic field confinement combined with molecular identification techniques, such as Raman spectroscopy, leads to SERS phenomena, which are useful for probing single molecules

Correspondence to: Jorge Ricardo Mejía-Salazar

E-mail: jrmejia3146@gmail.com

* Contribution to the centenary of the Brazilian Academy of Sciences. 
(Rodríguez-Lorenzo et al. 2009) and biomolecules (Xu et al. 2014). The challenges facing researchers and technologists are associated with making SERS detection feasible outside a specialized laboratory.

Here, the aim is to offer an overview of advances and strategies to improve plasmonic biosensing capabilities. We endeavor to give the reader an introduction to recent research efforts, which include the use of magnetic and magnetoplasmonic effects, incorporation of metamaterials in biosensing platforms, and novel SERS substrates to boost biosensing performance. For a comprehensive review of plasmonic biosensing we refer the reader to Refs. (Anker et al. 2008, Piliarik et al. 2009, Abbas et al. 2011, Nguyen et al. 2015, Henry et al. 2016, Bantz et al. 2011) and the references therein. The paper is organized in two main sections, the first of which deals with SPR biosensing platforms. It is mainly focused on the use of magnetic nanoparticles, magnetoplasmonic effects, and metamaterial-based SPR biosensing. The other main section is dedicated to plasmonic metallic nanostructures for SERS, where emphasis is placed on the detection and/or monitoring of analytes in trace levels. For both sections, a perspective for developments in the near future is presented, particularly with the challenges to take plasmonic sensing to real applications.

\section{SPR BIOSENSING}

SPRs are guided modes propagating along a metal/dielectric interface, in contrast to LSPRs that arise from light trapped at the surface of metallic nanoparticles smaller than the wavelength of the incident light. The wavevector for SPRs is $k_{\mathrm{SPR}}=k_{0} \sqrt{\frac{\varepsilon_{\mathrm{m}} n_{\mathrm{an}}^{2}}{\varepsilon_{\mathrm{m}}+n_{\mathrm{an}}^{2}}}$, where $n_{\mathrm{an}}$ is the analyte refractive index, $\varepsilon_{\mathrm{m}}$ is the permittivity of the metal, and $k_{0}=\frac{\omega}{c}$. Being guided modes, SPRs cannot be excited directly by light impinging from the dielectric. There are two conventional mechanisms to excite SPRs; the first one uses a prism with refractive index $n_{\mathrm{P}}>n_{\text {an }}$ where SPRs are excited through attenuated total reflection (ATR). ATR produces a surface wave with $k_{x}=k_{0} n_{\mathrm{P}} \sin \theta$, that is to be coupled with a SPR under the wavevector matching condition, i.e.,

$$
k_{0} n_{\mathrm{P}} \sin \theta=k_{0} \sqrt{\frac{\varepsilon_{\mathrm{m}} n_{\mathrm{an}}^{2}}{\varepsilon_{\mathrm{m}}+n_{\mathrm{an}}^{2}}} .
$$

The second mechanism to couple light to SPRs uses a diffraction grating. In this case, light impinging on a periodic grating is split into a series of beams with the wavevector along the interface altered as $k_{\|}+m G=$ $k_{\|}^{\prime}$, where $m$ is an integer, $G=\frac{2 \pi}{\Lambda}$ ( $\Lambda$ is the period length of the grating) is the grating wavevector, and $k_{\|}^{\prime}$ is the wavevector along the interface for the diffracted wave. SPR excitation will occur when the following condition is met

$$
k_{0} n_{\mathrm{an}} \sin \theta+\frac{2 \pi}{\Lambda} m=k_{0} \sqrt{\frac{\varepsilon_{\mathrm{m}} n_{\mathrm{an}}^{2}}{\varepsilon_{\mathrm{m}}+n_{\mathrm{an}}^{2}}} .
$$

The electromagnetic fields associated with SPRs are used in biosensing (Löfås et al. 1991, Homola 2008, Daghestani and Day 2010) for real-time monitoring of adsorption and biomolecular processes (Iwasaki et al. 2001, Deckert and Legay 1999, Karlsson 2004, Vutukuru et al. 2006, Shankaran et al. 2007, Wang et al. 2008, Koide et al. 2000, Gestwicki et al. 2001, Hu et al. 2004, Mao et al. 2011), with an operating principle based on the angle/wavelength shift of SPR due to changes in the analyte refractive index, $n_{\mathrm{an}}$. Significant changes are required, thus limiting its application to detection of molecules with high molecular-weight/concentration. In medical applications, in particular for cancer, there is the need to detect small concentrations, typically of the order of $\sim \mathrm{pg} \cdot \mathrm{mL}^{-1}$ for early diagnosis, of specific biomarkers such as proteins in human fluids, e.g. urine, 
blood, saliva, cerebrospinal fluids, or in tissues and tumor cells. Thus, the enhancement of SPR sensitivity to extend applications to biological, chemical and medical investigations has stimulated intensive research efforts to decrease the limits of detection. One of the main drawbacks in SPR biosensing is related with the broad SPR curves in conventional plasmonic sensing platforms, as the sensing performance depends on the sharpness of the SPR curve (Caballero et al. 2016). Recent biosensing platforms have been found to exhibit SPR curves narrower than for conventional structures, thus improving figures of merit (FoM). The aim of this section is to give an overview of some proposals to improve SPR sensitivity. In the first two Sections we will focus on the use of magnetic nanoparticles (MNPs) and magnetoplasmonic effects to amplify the SPR biosensor response to molecular binding effects, respectively, while the last section Section is devoted to metamaterials for the design of highly sensitive plasmonic platforms.

\section{MAGNETIC NANOPARTICLES}

The unique optical, electrical, catalytic, thermal and superparamagnetic properties of magnetic nanoparticles (MNPs) have been used for a number of chemical and biochemical purposes (Li et al. 2013, MolinerMartinez et al. 2011, Chen et al. 2011, Tang and Lo 2013, Ambashta and Sillanpaa 2010, Oh and Park 2011, Colombo et al. 2012, Huang and Juang 2011, Aguilar-Arteaga et al. 2010, Beveridge et al. 2011, CarregalRomero et al. 2013, Iranifam 2013, Xu and Wang 2012, Cannon et al. 2012, Mani et al. 2011, Tseng et al. 2009, Bruls et al. 2009). MNPs can work as a concentration/purification agent, as well as an amplifier for detection due to their high surface-to-volume ratios (Soelberg et al. 2009, Wang et al. 2010, 2011, Liang et al. 2012), which offers higher density of chemical bindings. In order to amplify the SPR signal and reduce the background interferences (purification), a SPR biosensing platform was developed to detect staphylococcal enterotoxin B (SEB) (molecular weight $28.4 \mathrm{kDa}$ ) by using antibody-coated paramagnetic nanobeads (50 $\mathrm{nm}$ sized), with a resolution of approximately $1 \times 10^{-6}$ refractive index units (RIU) (Soelberg et al. 2009). Fig. 1a shows a sequential three-step protocol for detecting SEB, with demonstration of a large amplification of the SPR signal. The three-step sequence is as follows: (1) direct detection of free SEB in buffer solution, (2) amplification with $50 \mu \mathrm{g} / \mathrm{mL}$ biotinylated anti-SEB antibodies, and (3) a secondary amplification with streptavidin-nanobeads ( $200 \mu \mathrm{L}$ stock $\mu$ MACS beads in $2 \mathrm{~mL}$ total buffer) that bind to the captured biotinylated anti-SEB antibodies. A schematic representation of the three steps is shown in Fig. 1b, where the relative size of each particle is depicted.

In another example, Wang et al. (Wang et al. 2010) demonstrated an amplified SPR signal by using $\mathrm{Fe}_{3} \mathrm{O}_{4}$ MNPs of two different sizes and modified with carboxyl groups, assembled on amino group modified SPR gold substrate. The SPR angle shifts can be seen in Fig. 2 for different concentrations of $\mathrm{Fe}_{3} \mathrm{O}_{4} \mathrm{MNPs}$ with average diameters of $14.51 \mathrm{~nm}$ and $32.82 \mathrm{~nm}$. The corresponding averaged diameters of $\mathrm{Fe}_{3} \mathrm{O}_{4} \mathrm{MNPs}$ were obtained from the TEM images and size distribution functions in Fig. 3. This amplified SPR signal with MNPs can be exploited by using $\mathrm{Fe}_{3} \mathrm{O}_{4}$ MNPs - aptamer conjugates as the amplification reagent. In particular, Wang et al. (Wang et al. 2010) reported an improved sensitivity to detect adenosine in the range of $10-10^{4} \mathrm{nM}$ by employing $\mathrm{Fe}_{3} \mathrm{O}_{4} \mathrm{MNPs}$ - antiadenosin aptamer conjugates in an indirect inhibition assay, as shown in Fig. 4.

The application of MNPs for the quick delivery of an analyte to the sensor surface through a magnetic field gradient, thus overcoming a slow diffusion-driven mass transfer, has been proven in optical biosensing (Tseng et al. 2009, Bruls et al. 2009). The functionality of MNPs combined with signal amplification, i.e., 

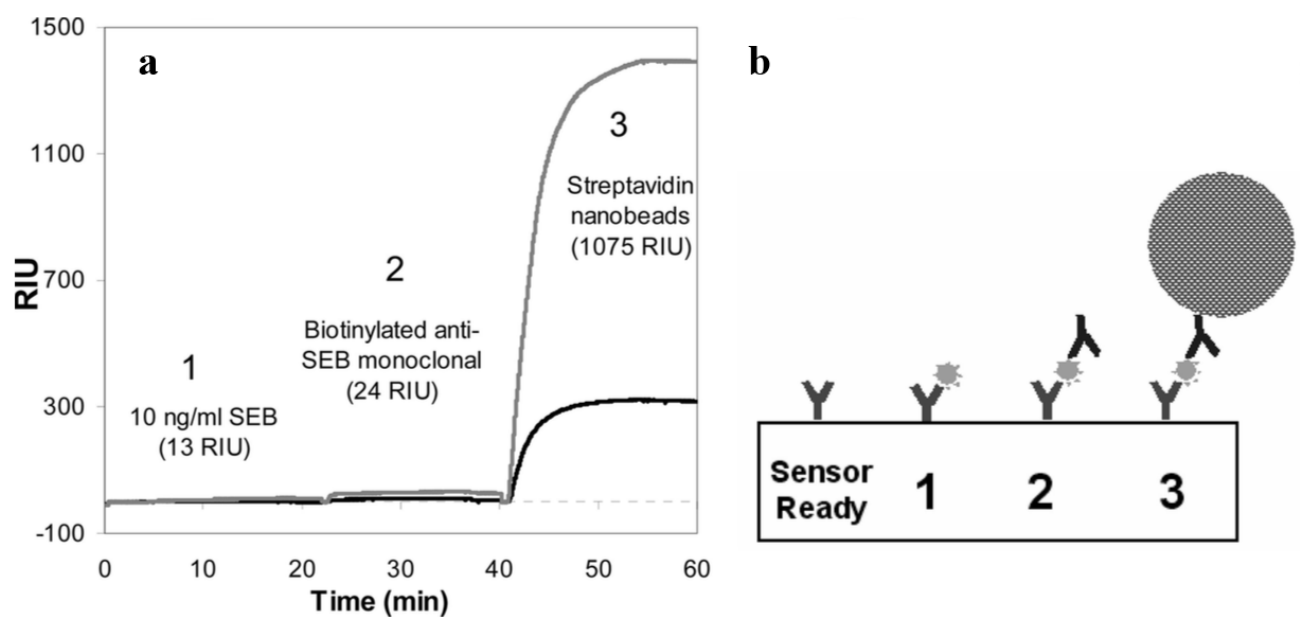

Figure 1 - (a) Sequential protocol for detection and signal amplification. (1) Detection of $10 \mathrm{ng} / \mathrm{mL}$ SEB in PBS, (2) amplification with antibodies, and (3) secondary amplification with nanobeads. (b) Pictorial representation of the sensor surface and amplification steps. Reproduced with permission from Soelberg et al. (2009).

MNPs simultaneously working as "vehicles" for rapid delivery of target analyte from a sample to the sensor surface and as labels increasing the measured refractive index changes associated with the binding of target analyte, in SPR biosensors was proposed by Y. Wang et al. (Wang et al. 2011). The idea consists in the use of a metal grating coupler for SPR excitation, with a magnetic field gradient applied through the sensor chip, as shown in Fig. 5, for manipulating MNPs on its surface. The grating coupler was used instead of the conventional prism-based Kretschmann configuration (Kretschmann and Raether 1968). MNPs were conjugated with antibodies for detection of $\beta$ human chorionic gonadotropin ( $\beta$ hCG). A magnetic field was used to capture the MNPs-antibody-analyte on the sensor surface, thus improving the sensitivity by four orders of magnitude when compared with the regular SPR direct detection.

These few examples demonstrated the potential of MNPs to improve SPR biosensing, especially in decreasing the limits of detection. Therefore, using MNPs should be further investigated with other types of analytes, as several limitations still remaining in SPR biosensing could be overcome.

\section{MAGNETOPLASMONIC EFFECTS FOR THE DESIGN AND DEVELOPMENT OF BIOSENSING PLATFORMS}

There has been an increasing research interest in magnetoplasmonic effects to improve SPR sensitivity (Sepúlveda et al. 2006, Regatos et al. 2010, 2011, Manera et al. 2011, 2012, 2014, Chou et al. 2014, Caballero et al. 2016, Ignatyeva et al. 2016, Grunin et al. 2016, Maccaferri et al. 2015). This mechanism was proposed by Sepúlveda et al. (2006), where magneto-optical (MO) activity was combined with SPRs for decreasing the limit of detection of a Kretschmann-like SPR platform. Sensing takes place by monitoring the transverse magneto-optical Kerr effect (TMOKE), with narrow Fano-like resonances, which is sensitive to small variations of dielectric properties of the surrounding material. Several geometrical configurations and plasmonic systems were reported. For example, Ignatyeva et al. (Ignatyeva et al. 2016) proposed a onedimensional photonic crystal for ultranarrow SPRs, with even sharper TMOKE resonances, to improve the sensitivity of a Kretschmann-like SPR sensor for detecting butane and helium. Fig. 6 depicts the experimental setup and the corresponding plasmonic structure used to measure the SPR and TMOKE signals, whose 


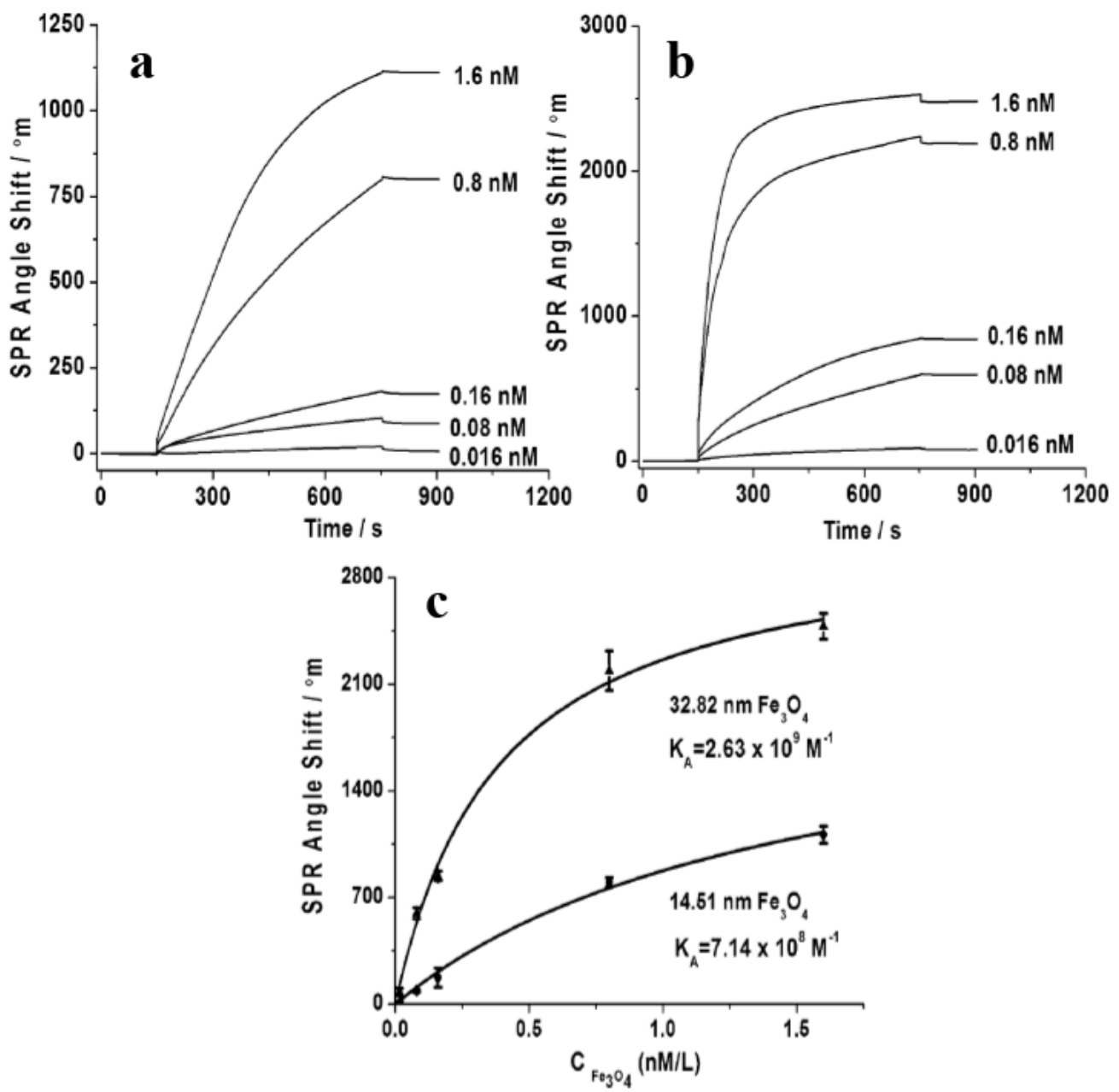

Figure 2 - (a) and (b) show the time-dependence of the SPR-angle interrogation for different concentrations of $\mathrm{Fe}_{3} \mathrm{O}_{4} \mathrm{MNPs}_{\mathrm{s}}$ with average sizes $14.51 \mathrm{~nm}$ and $32.82 \mathrm{~nm}$, respectively. (c) Comparative results are presented for the average sizes $14.51 \mathrm{and} 32.82 \mathrm{~nm}$. Reproduced with permission from Wang et al. (2010). 

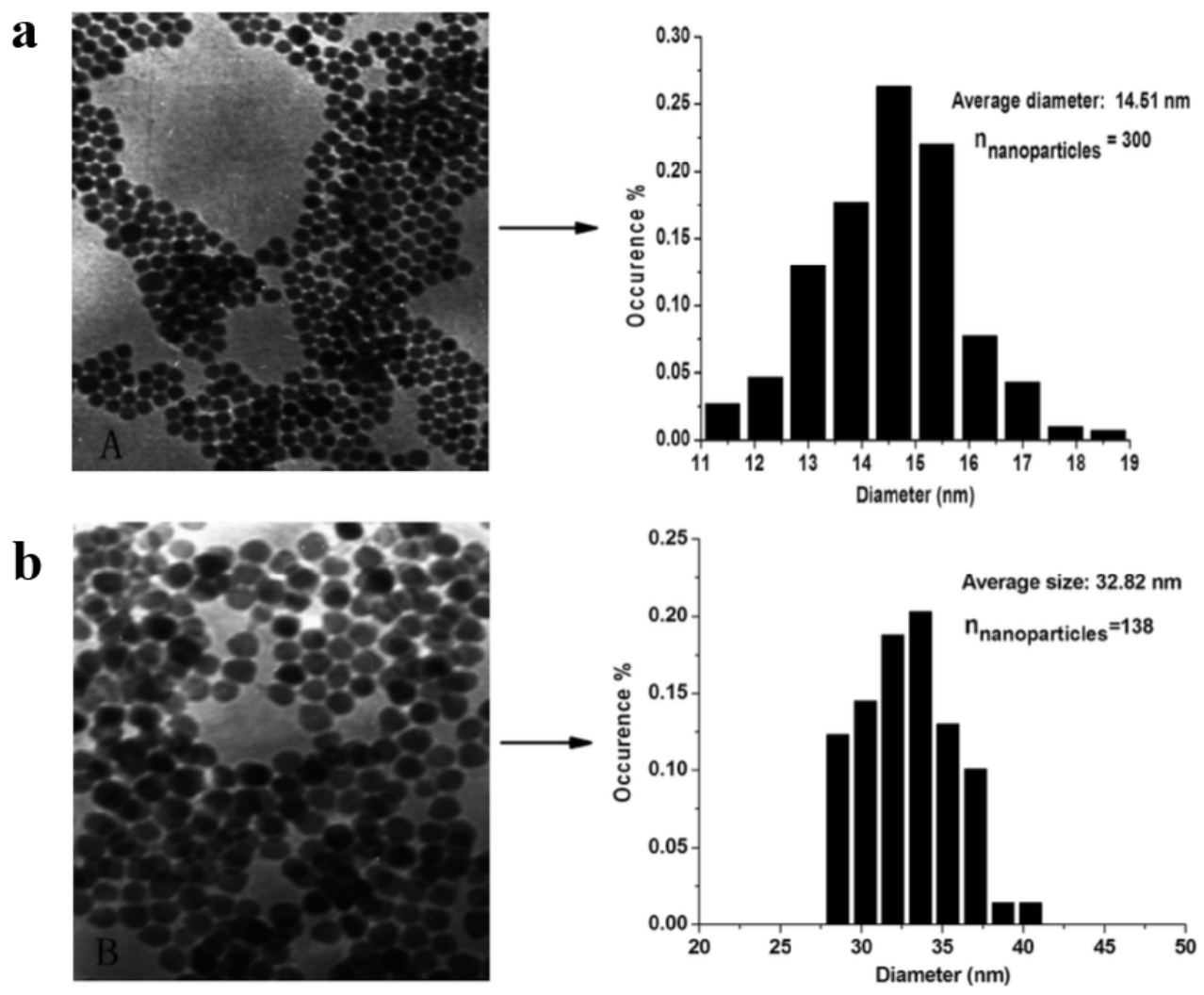

Figure 3 - TEM pictures of $\mathrm{Fe}_{3} \mathrm{O}_{4}$ MNPs with average sizes (a) $14.51 \mathrm{~nm}$ and (b) $32.82 \mathrm{~nm}$, with the corresponding histograms for size distribution on the right hand side. Reproduced with permission from Wang et al. (2010).

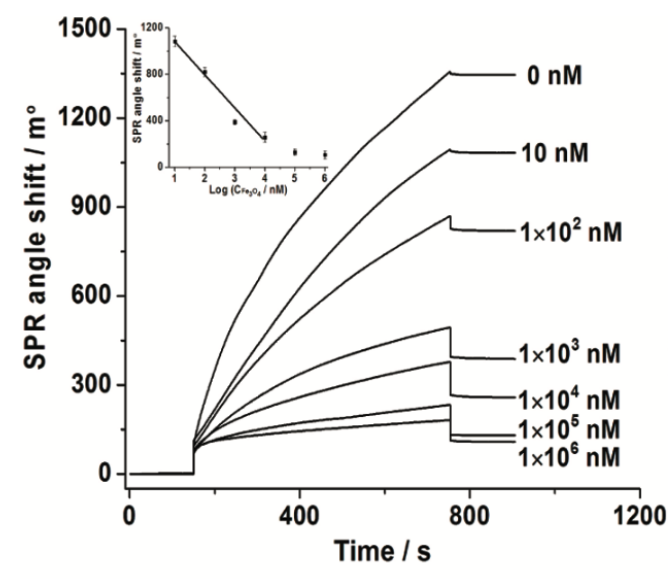

a

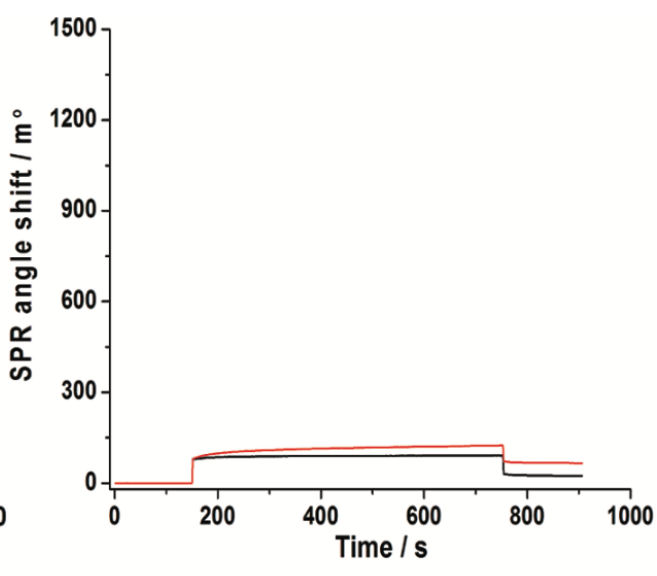

b

Figure 4 - (a) Time dependence of the SPR-angle shift for various concentrations of adenosine. $\mathrm{The}_{3} \mathrm{O}_{4} \mathrm{MNP}_{4}$-antiadenosine aptamer conjugates reacted with different samples for $30 \mathrm{~min}$ before measurements were carried out. A linear relationship between the logarithms of adenosine concentrations and the SPR angle shift can be noted in the inset. (b) The red and black lines show the time-dependence for the SPR angle with $1 \mu \mathrm{M}$ antiadenosine aptamer without adenosine and after reaction with $1 \mathrm{mM}$ adenosine for $30 \mathrm{~min}$, respectively. Reproduced with permission from Wang et al. (2010). 


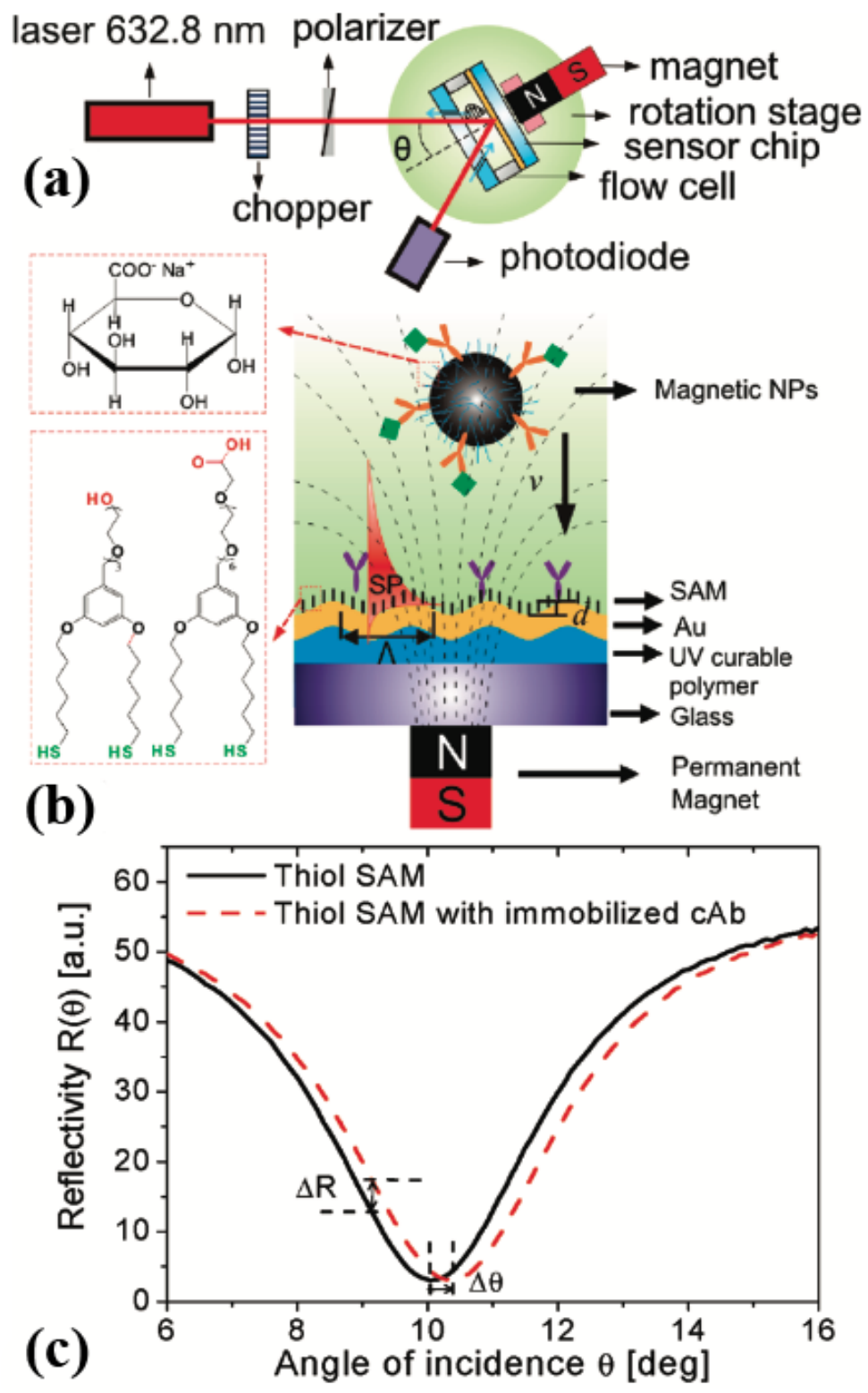

Figure 5 - (a) Pictorial representation of the optical setup and (b) the GC-SPR-based sensor with MNPs for enhanced signal. (c) Solid and dashed lines are for the reflectivity before and after immobilization of the captured antibodies. Reproduced with permission from Wang et al. (2011). 
results are shown in Fig. 7. Note the narrower TMOKE resonances in comparison with SPR ones. Also significant is that Ignatyeva et al. (Ignatyeva et al. 2016) compared their results with those of a theoretical system with optimal geometrical parameters, and suggested that optimizing parameters of the photonic crystal building layers may allow for even higher quality factors and sensitivity.

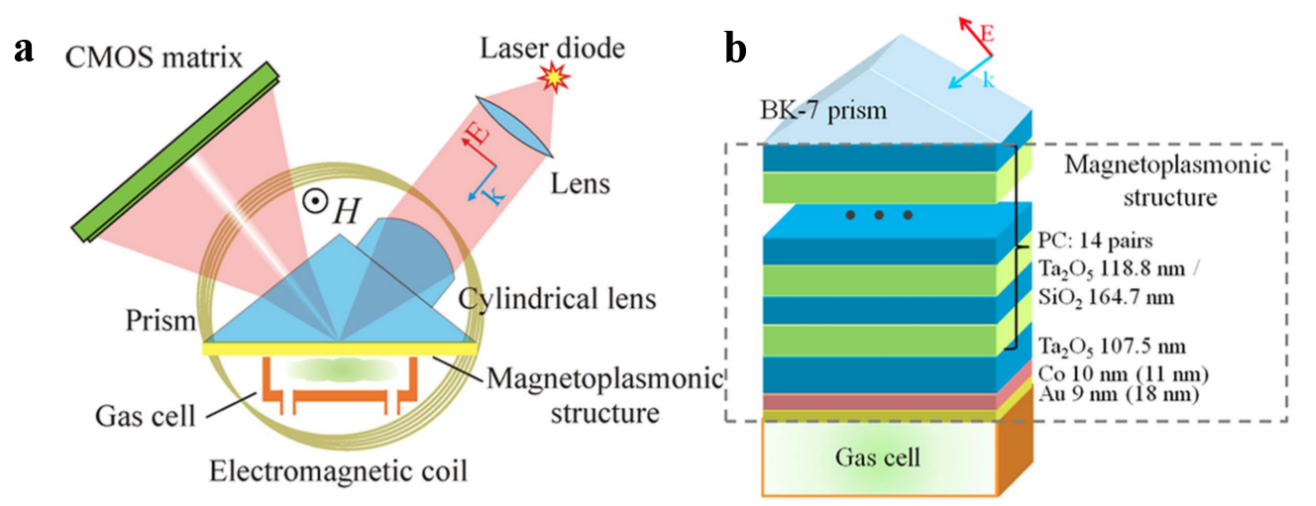

Figure 6 - (a) Pictorial view of the experimental setup and (b) Kretschmann-like magnetoplasmonic sensing platform. Reproduced with permission from Ignatyeva et al. (2016).

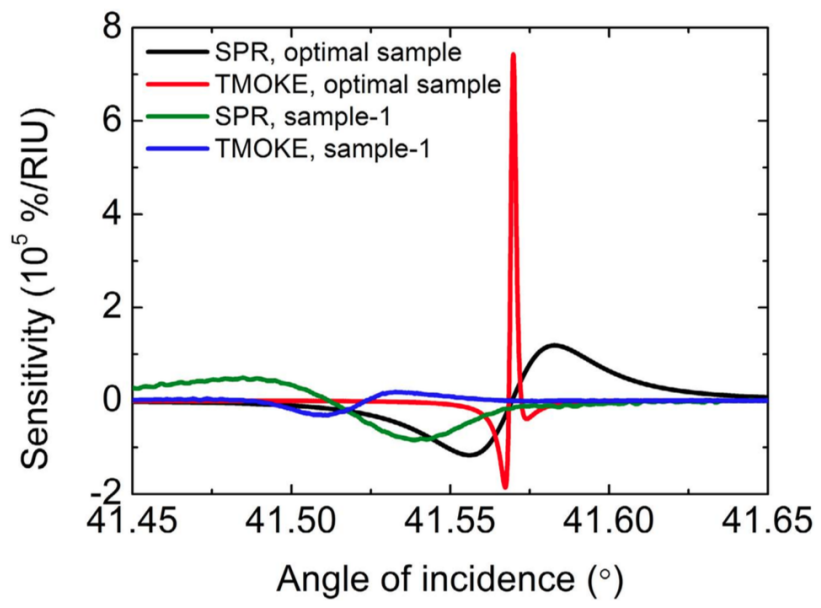

Figure 7 - Comparison of SPR and TMOKE signal sensitivity to the refractive index variation for the sample-1 (experimental data) and an optimal sample (theory). Reproduced with permission from Ignatyeva et al. (2016).

Another proposal to use a magnetoplasmonic grating-coupler trilayer structure for sensitive sensors was implemented with the corresponding changes in reflectance $(\mathrm{R})$ and TMOKE $(\boldsymbol{\delta})$ measured as functions of the wavelength for increasing concentrations of glycerol in a microfluidic cell(Grunin et al. 2016). A 6-fold increase in performance was reported in terms of sensitivity and limit of detection, when TMOKE was used instead of the usual SPRs.

In the most recent proposal to use TMOKE for improving SPR biosensing capabilities, Caballero et al. (Caballero et al. 2016) employed a MO slab made of Co sandwiched in between two metallic nanohole arrays made of $\mathrm{Au}$, as shown in Fig. 8. They were able to estimate a 2-order of magnitude larger bulk figure of merit when compared with other previous SPR sensors. This improvement was reached through the interplay between the MO properties of the ferromagnetic slab combined with the excellent plasmonic 
properties of noble metals. Extremelly sharp Fano-like features were observed in the MO response, which in addition are very sensitive to the dielectric properties of the surrounding medium, as seen in Fig. 9.

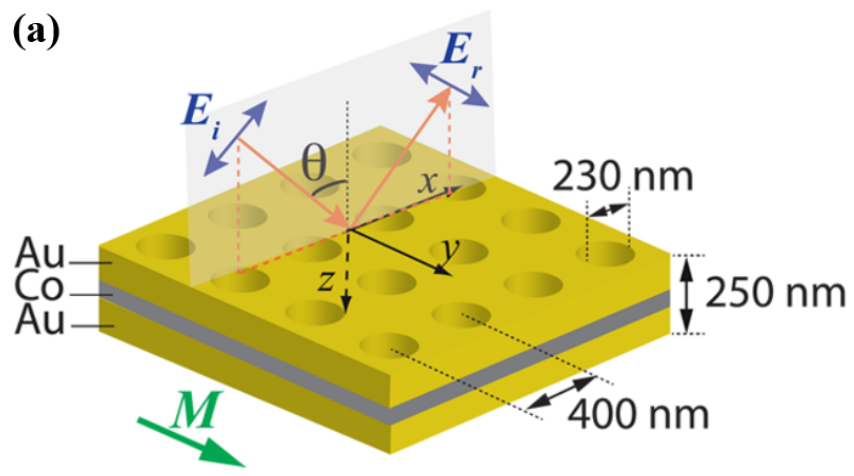

(b)

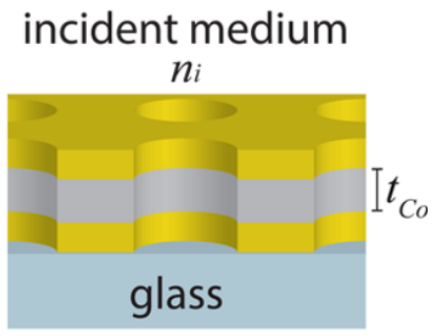

Figure 8 - (a) Scheme of the Au-Co-Au periodically perforated membrane. Geometrical parameters considered in calculations are given in this figure, where $t_{\mathrm{Co}}$ corresponds to the Co thickness. The Co magnetization, $M$, is taken as parallel to the the plane of the membrane and normal to the incidence plane. (b) Lateral view of the hybrid membrane, considered as placed on a glass substrate. Reproduced with permission from Caballero et al. (2016).

\section{METAMATERIALS TO BOOST THE PERFORMANCE OF PLASMONIC BIOSENSING}

Recent progress in microstructuring and numerical modeling techniques allow for the manipulation and control of light at micro and nanoscale through the design and development of artificial materials, known as metamaterials, with no naturally occurring dielectric and magnetic properties (Pendry et al. 1999, Smith et al. 2000, Shelby et al. 2001, Eleftheriades et al. 2002, Wu et al. 2007, Valentine et al. 2008, Gong et al. 2014, Lee et al. 2016). These man-made materials are revolutionizing and opening several new technological areas. In biomedical applications, one expects to reach major technological breakthroughs in the next few decades by incorporating metamaterial properties to design biotechnological devices. For example, metamaterials are being used to improve the limit of detection in plasmonic sensing/biosensing platforms by their incorporation as one of the building components (Kabashin et al. 2009, Liu et al. 2010, Wu et al. 2012, Cao et al. 2013, Shen et al. 2013, Kravets et al. 2013, Sreekanth et al. 2016). The experimental realization of a metamaterial-based plasmonic transducer with an array of parallel gold nanorods oriented perpendicularly to a glass substrate was made(Kabashin et al. 2009). The structural parameters of such array of parallel, electrochemically grown gold nanorods, occupying an area of up to $2 \mathrm{~cm}^{2}$, were controlled to have the lateral size and separation between the nanorods much smaller than the working wavelength. This was necessary for the system to be well described using an effective medium model, since individual nanorod sizes have no influence (or negligible) on the optical properties. A guided mode was excited with the field distribution inside the layer determined by plasmon-mediated interaction between the nanorods. Having similar resonant excitation conditions to SPRs, this resonant mode was highly sensitive to changes in refractive of more than $30.000 \mathrm{~nm} \cdot \mathrm{RIU}^{-1}$. The potential of that platform for sensing purposes was demonstrated by connecting a flow of glycerine in aqueous solution to the prism-based coupling block to provide minute changes of the bulk refractive index of the nanorod surroundings. A redshift in the resonance was observed in response to an increase in the refractive index, analogously to conventional SPR-based sensing. Additional tests using the 

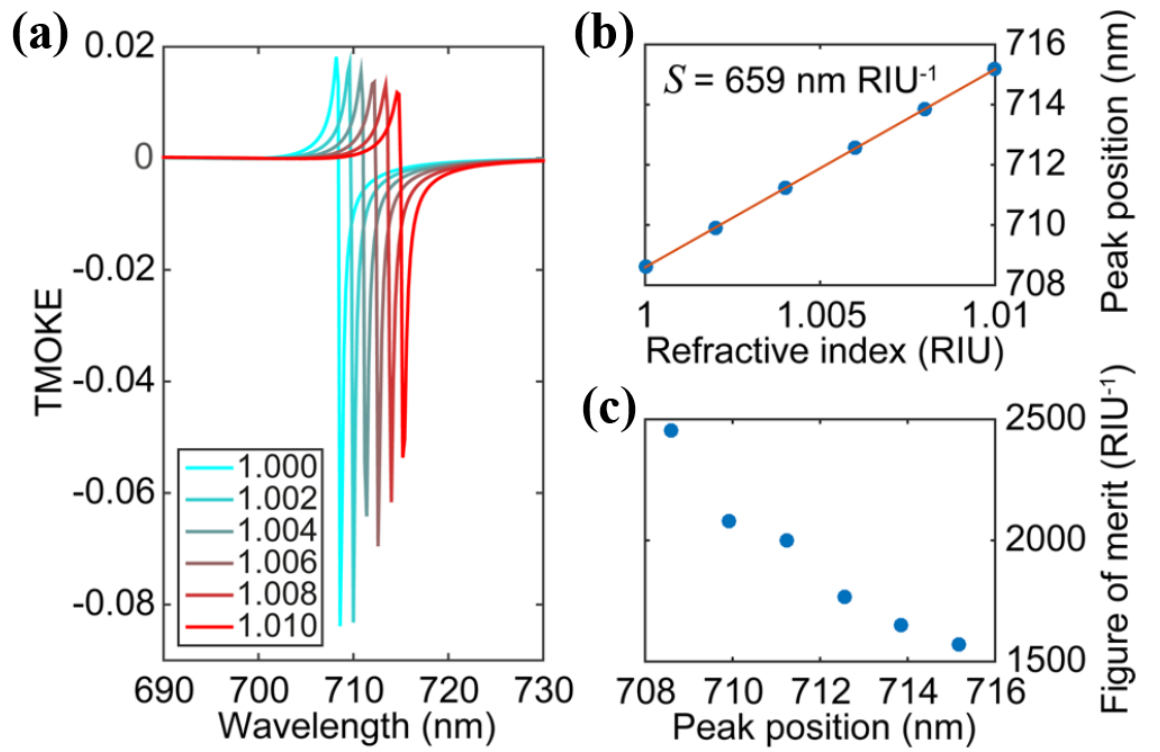

Figure 9 - (a) TMOKE as a function of the wavelength for the system in Fig. 8 with $t_{\mathrm{Co}}=110 \mathrm{~nm}$. Results are shown for different values of the refractive index, $n_{i}$. (b) The solid circles correspond to the Fano-like features as a function of $n_{i}$ from (a), while the solid line corresponds to their linear regression fit. The slope, $S=\Delta \lambda / \Delta n_{i}=659 \mathrm{~nm} \cdot \mathrm{RIU}^{-1}$, defines the sensitivity of the system. (c) Figure of merit as a function of the wavelength. Reproduced with permission from Caballero et al. (2016).

streptavidin-biotin affinity model led to detection limits of ca. $300 \mathrm{nM}$, while detection of biotin (molecular weight of $244 \mathrm{Da}$ ) by conventional SPR requires concentrations of at least $100 \mu \mathrm{M}$.

Sreekanth et al. (2016) proposed a sensitive biosensing plasmonic platform based on hyperbolic metamaterials (HMMs), which are characterized by one of the principal components of their permittivity $(\varepsilon)$ or permeability $(\mu)$ tensor having opposite sign to the other two principal components (see details in Poddubny et al. (2013)). The structure was developed with a perforated gold layer, working as a grating to excite SPRs, on the top of a HMM consisting of 16 alternating layers of gold $(\mathrm{Au})$ and aluminum dioxide $\left(\mathrm{Al}_{2} \mathrm{O}_{3}\right)$. This system was integrated with a microfluidic channel and the reflectance spectra for $p$-polarized light under four different angles of incidence were measured to demonstrate the excitation of SPRs. This platform was also used for biosensing purposes with the streptavidin-biotin affinity model in which a quantification of 10 pM biotin in a phosphate buffered saline (PBS) solution could be obtained by monitoring the wavelength shift in the reflectance spectrum as the biotin concentration varied from $10 \mathrm{pM}$ to $1 \mu \mathrm{M}$. Recent proposals are based on sharp phase changes from topologically protected zero reflection (Kravets et al. 2013), for label-free single-molecule detection, and the simultaneous probing of conformational states and binding affinity of biomolecules through the proper design of highly tunable metamaterials (Cao et al. 2013).

\section{A PERSPECTIVE IN METAMATERIAL-BASED SPR BIOSENSING}

Miniaturization of conventional SPR platforms in the Kretschmann configuration is impaired owing to the requirement of a prism with refractive index larger than the refractive index of the dielectric background for SPR excitation. Traviss et al. (2013) have recently achieved excitation of SPRs without the need of a prism or grating coupler, through the perfect absorbing ENZ-mode (Vassant et al. 2012) in nanostructured indium tin oxide (ITO) films operating in the $\varepsilon$-near-zero (ENZ) frequency regime (Yoon et al. 2015, Feng 
and Halterman 2012, Park et al. 2015) coupled to the allowed SPP mode at the ENZ/Metal interface for p-polarized incident light. Since ITO films are amenable to functionalization with phosphonates (Gardner et al. 1995), amines (Oh et al. 1999), zirconium complexes (VanderKam et al. 1999), carboxylic acids and thiols (Yan et al. 2000), DNA (Armistead et al. 2000), and silanes (Markovich and Mandler 2001), this principle of excitation for SPRs may be exploited in the design of highly integrated plasmonic biosensing platforms.

\section{SERS WITH PLASMONIC NANOSTRUCTURES}

SERS involves the excitation of surface plasmons on metallic nanostructures, resulting in the enhancement of the electromagnetic (EM) field (Moskovits 1978). The enhanced EM field is experienced by molecules in the vicinity of the nanostructures (Gersten and Nitzan 1981) and is achieved only for nanostructures capable of sustaining localized surface plasmon resonances (LSPRs), which includes gold, silver and copper (Kneipp et al. 2006, Aroca 2007, Maier 2007, Le Ru and Etchegoin 2009). The challenge of single molecule detection (Nie and Emory 1997, Kneipp et al. 1997) brought the need for higher enhancements of the EM field, which was achieved on the so-called "hot spots", where the enhancement factor reaches up to $10^{10}$ (Nie and Emory 1997, Kneipp et al. 1997). The hot spots have the property to concentrate an incident EM field and effectively amplify the near field between and in the vicinity of the nanostructures (Le Ru et al. 2011). In addition to nanospheres (Michaels et al. 2000, Xu et al. 1999, 2004), nanostructures of different shapes have been made to enhance EM fields for SERS. By controlling the shape of the nanostructures, one can control the ways in which electrons oscillate, consequently tuning how the nanostructure scatters and/or absorbs light, and enhances local EM fields (Tiwari et al. 2007). Nanostructures containing sharp protrusions, such as nanostars (Hao et al. 2007, Chatterjee et al. 2016, Atta et al. 2016, Oliveira et al. 2017), nanorices (Wei et al. 2010) and bipyramids (Le Ru et al. 2011, Niu et al. 2017), and also sharp corners, as nanorods (Yang et al. 2012, Sivapalan et al. 2013, Greeneltch et al. 2013, Kumar et al. 2014), nanotriangles (Sherry et al. 2006, Haes and Van Duyne 2002, Scarabelli et al. 2014), nanoprisms (Métraux and Mirkin 2005, Ciou et al. 2009) and nanocubes (McLellan et al. 2007, Wu et al. 2012), have been designed to create regions with strongly enhanced EM fields, i. e., the hot spots. Fig. 10 shows electron microscopy (scanning/SEM or transmission/TEM) images of various shapes of nanostructures and their respective electric fields simulated by computational methods (Atta et al. 2016, Wei et al. 2010, Li et al. 2013).

Because hot spots are located at interparticle gaps (junctions) or at sharp edges of the metallic nanostructures (Hatab et al. 2010, Fang et al. 2008, Oh and Jeong 2012, Wang et al. 2010), it is normally difficult to obtain reproducibility in terms of signal intensity, essentially due to the non-uniform excitation of the target molecules experiencing the inhomogeneous near field at narrow hot spots (Hatab et al. 2010, Fang et al. 2008). Many efforts have been made to obtain metallic nanostructures with homogeneous and reproducible SERS signal, including direct metal deposition (Oh and Jeong 2012), assembly of metallic nanostructures (Wang et al. 2010, Zhou et al. 2011, Huang et al. 2013), or even more sophisticated techniques, such as decorating nanowires with small metallic nanospheres onto the silver nanowire (Seung et al. 2008). The challenge is to increase the number and uniformity of hot spots, producing metallic nanostructures with extended regions of homogeneous, intense near field (Fang et al. 2008, Chen et al. 2015). A beautiful example of this control was produced by coupling silver nanohelices (Caridad et al. 2017). The noticeable near field distribution is due to dipole-dipole interaction between different turns: surface charges of one sign are 

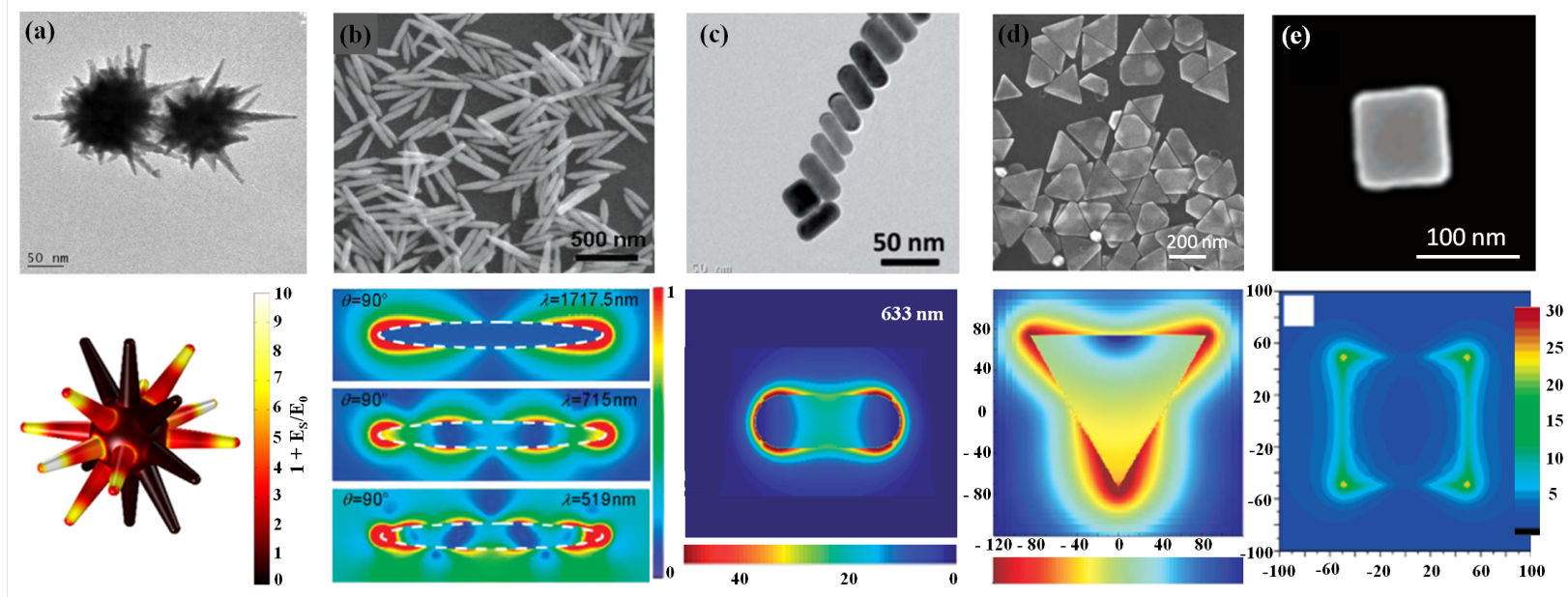

Figure 10 - Electron microscopy images of nanostructures and corresponding electric fields: (a) nanostars (Atta et al. 2016), (b) nanorices (Wei et al. 2010), (c) nanorods (Kumar et al. 2014), (d) triangular nanoprisms (Li et al. 2013), and (e) nanocubes (McLellan et al. 2007). TEM images are represented in (a) and (c) and SEM in (b), (d), and (e). Simulations using COMSOL Multiphysics were carried out in (a) and (b), while the FDTD method was used in (c), (d), and (e). Reproduced with permission (Atta et al. 2016, Wei et al. 2010, Kumar et al. 2014, McLellan et al. 2007, Li et al. 2013).

accumulated on one side of the nanohelix, whereas the opposite charge is accumulated on the other side, see Fig. 11a. The regular hot spot distribution of a single nanohelix allows for a unique coupling of the silver nanohelices, in which a weak coupling generates large regions of high and uniform electromagnetic enhancement, called "hot-volumes", as shown in Fig. 11b (Caridad et al. 2017). As a result of the "hot volumes", SERS spectra from random regions showed high reproducibility of the SERS signals, with standard deviation around $10 \%$, observed in Fig. 11c.

Significant advances have been made in fabricating metallic nanostructures capable of achieving high EM field enhancements by generating regions containing uniform distributions of homogeneous hot spots (Hatab et al. 2010, Fang et al. 2008, Chen et al. 2015). Polymeric matrices (Wu et al. 2012, Fortuni et al. 2017) and polymeric surfaces (Zhang et al. 2008, Chen et al. 2010) were used for fabricating SERS substrates with such characteristics. The high transparency, elasticity, stability, and applicability, as a planar support for metallic nanostructures attachment via functionalization (Singh et al. 2012, Shiohara et al. 2014), are some of the advantages of working with polymeric materials. Fortuni et al. (2017) reported a one-step in situ synthesis of gold nanostars (AuNSs) on a polydimethylsiloxane (PDMS) film, in which a gold ion solution containing a reducing agent and a stabilizer was dropped onto the PDMS layer. The SERS activity of the substrate was demonstrated by adsorbing a monolayer of 4-mercaptobenzoic acid (4-MBA) onto its surface, of which the SERS mapping displayed in Fig. 12a was obtained. Then, a real system was investigated by detecting trace levels of the pesticide thiabendazole (TBZ) on apple skin, as detailed in Fig. 12b. Therefore, the one-step AuNSs substrates have low cost and may be produced with a simple, fast fabrication procedure, and can also be made mechanically flexible.

SERS substrates containing plasmonic satellites covering dielectric particles, such as raspberry-like nanoclusters, also exhibit attracting plasmonic properties (Romo-Herrera et al. 2011, Qian et al. 2015), with large SERS signals due to the generation of hot spots in the clusters (Pasquale et al. 2011). They consist 

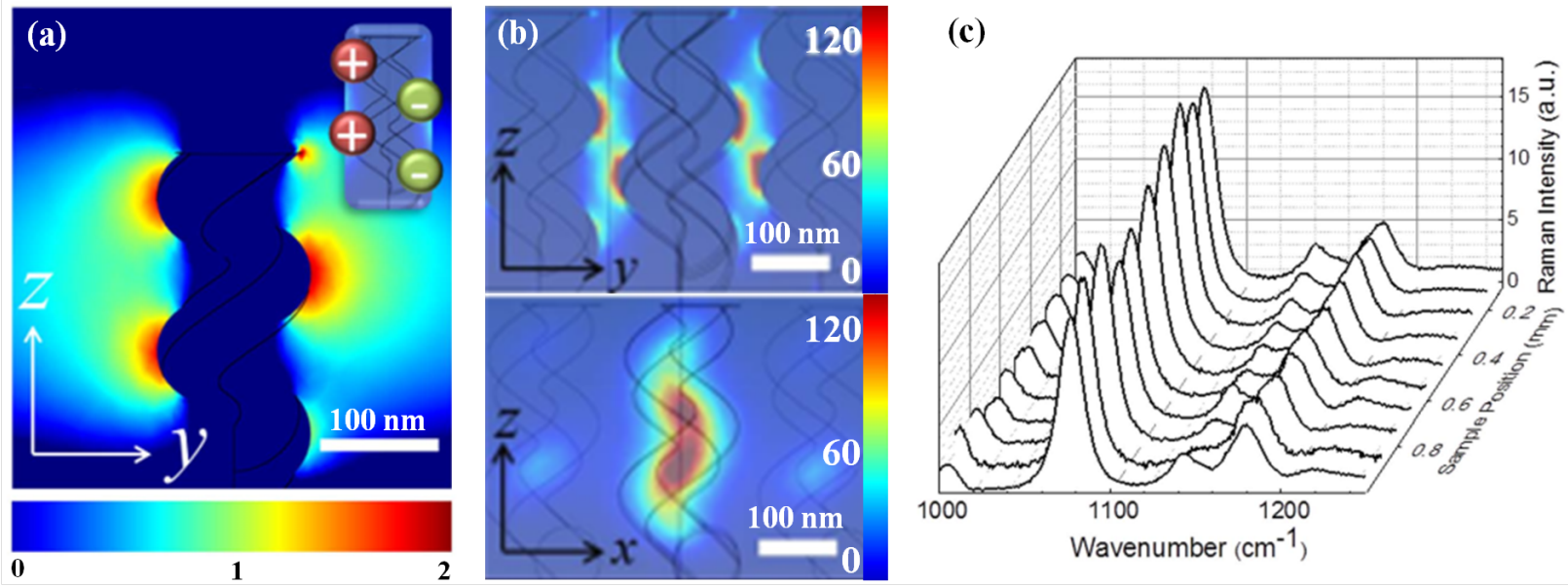

Figure 11 - Near field intensity distribution of (a) single nanohelix, and (b) array of silver nanohelices weakly coupled. The inset in (a) shows the dipole distribution existing in a single nanohelix. (c) SERS spectra of $p$ MA on array of silver nanohelices for 10 random regions. Reproduced with permission (Caridad et al. 2017). Copyright 2017, Nature Publishing Group.
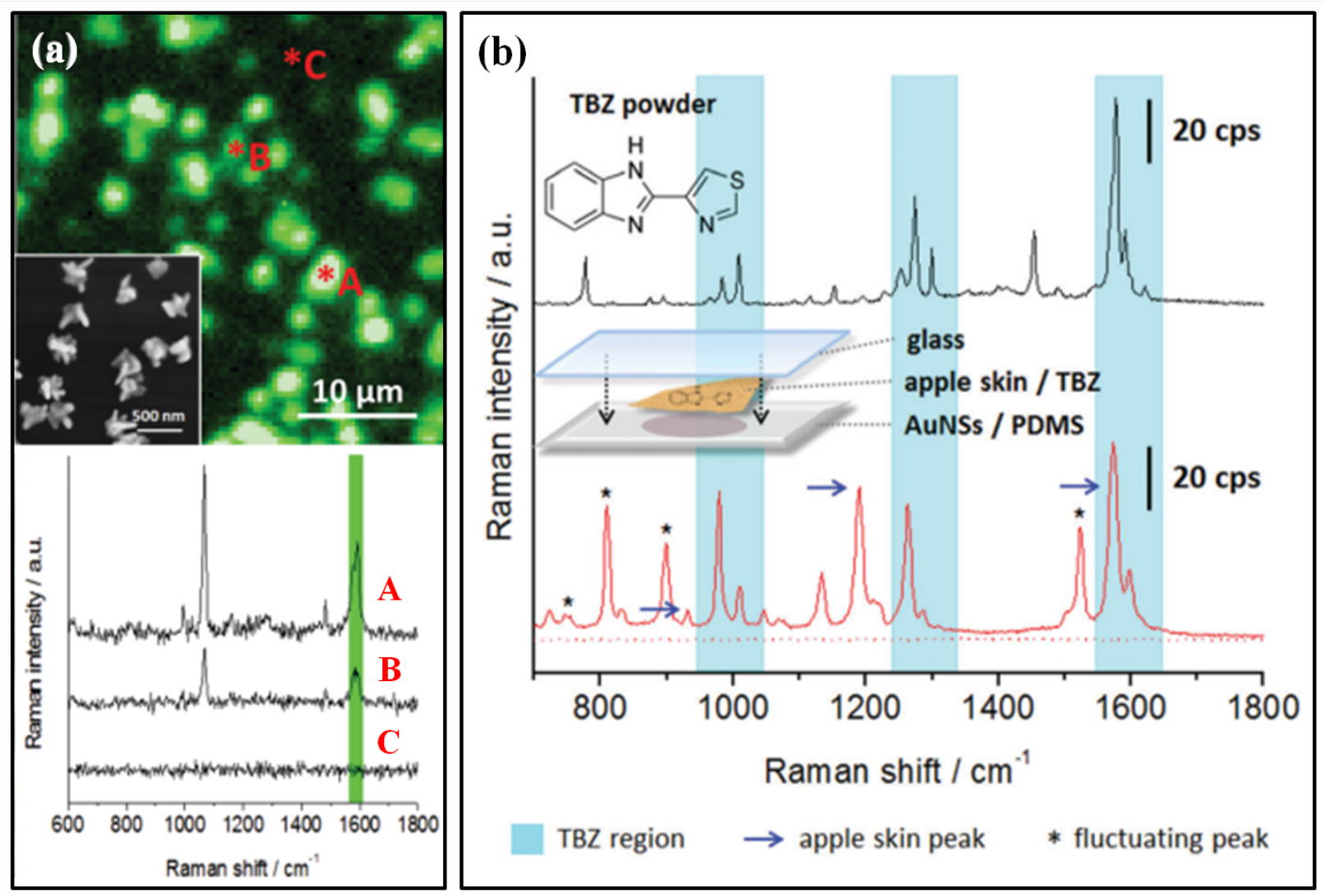

Figure 12 - (a) SERS mapping of 4-MBA and SERS spectra corresponding to 3 different positions on the mapping (A, B, and C). The inset shows a SEM image of AuNSs on the PDMS film. (b) Raman spectrum of TBZ powder (black line) and TBZ (10 ${ }^{-5} \mathrm{~mol} / \mathrm{L}$ ) adsorbed onto apple skin (dashed red line), and SERS spectrum of TBZ $\left(10^{-5} \mathrm{~mol} / \mathrm{L}\right)$ recorded from the apple skin on AuNSs/PDMS (solid red line). The insets display the chemical structure of TBZ and a schematic illustration of the sample configuration. Reproduced with permission (Fortuni et al. 2017). Copyright 2017, Royal Society of Chemistry. 
of dielectric particles, which can be silica cores, wrapped within layers of polyelectrolytes to promote a shell of positive charges to further anchor the negative charges of the plasmonic satellites, which are gold or silver nanospheres (Le Beulze et al. 2017). By tuning the size and density of the satellites, one can modify the spectral position and extinction of the raspberry-like clusters, offering new possibilities for the ultrasensitive screening of analytical targets (Le Beulze et al. 2017). Fig. 13 shows the influence of size and density of satellites on the extinction of raspberry-like clusters made of $106 \mathrm{~nm}$ polyelectrolyte-coated silica and satellites of gold nanospheres (AuNPs) with different diameters.
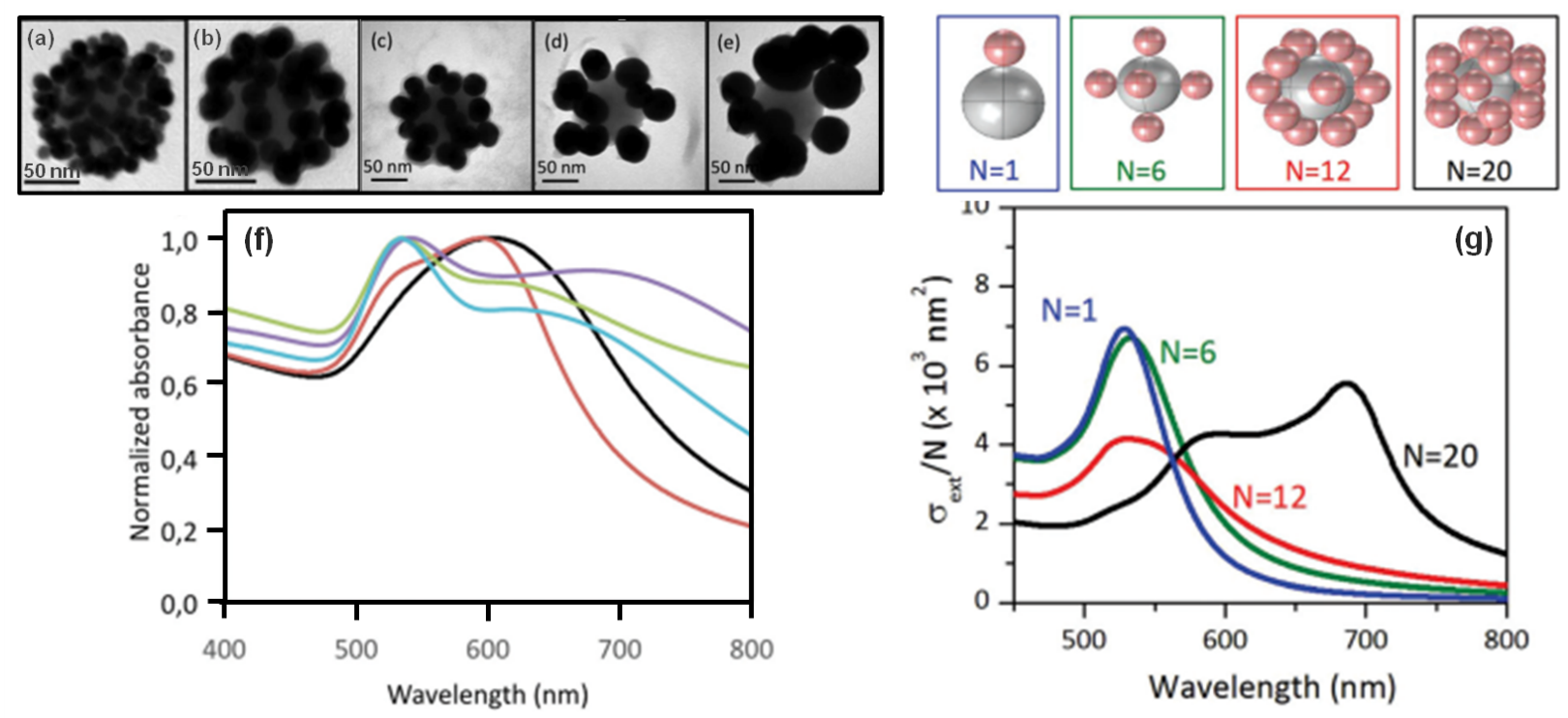

Figure 13 - TEM images of raspberry-like clusters made of $106 \mathrm{~nm}$ polyelectrolyte-coated silica and AuNPs with different diameters: (a) 10, (b) 20, (c) 30, (d) 40 and (e) $50 \mathrm{~nm}$, and their corresponding (f) UV-Vis absorption spectra for 10 (black), 20 (red), 30 (green), 40 (pink) and $50 \mathrm{~nm}$ (yellow) AuNPs. (g) Computed extinction spectra of raspberry-like clusters with N =1, 6, 12 and 20 satellites of AuNPs with $50 \mathrm{~nm}$ of diameter. Adapted from Le Beulze et al. (2017). Copyright 2017, Royal Society of Chemistry.

SERS substrates based on metallic nanostructures have been used in sensors and biosensors (Song et al. 2017, Kumar et al. 2017, Gandra et al. 2016), where the coupling of near field with vibrational modes of target molecules yields an enhanced SERS signal by several orders of magnitude (Sivashanmugan et al. 2015). The limitations of SERS sensing are related to the need of achieving reproducible SERS signals, which require the fabrication of homogeneous, sensitive substrates containing large, uniform regions of hot spots. The cost, complexity of fabrication, and flexibility of the substrates are other considerations for applications (Sivashanmugan et al. 2015, Akin et al. 2014). Recent research has been directed toward the design of SERS sensor platforms (Song et al. 2017, Kumar et al. 2017, Bibikova et al. 2017) and SERS nanoprobes (Gandra et al. 2016, Li et al. 2015, Lee et al. 2012), such as the nanoprobes highly stable under harsh physiological conditions for in vitro and in vivo biosensor analysis (Goodman et al. 2014). Lee et al. (2012) were the first to report simultaneous SERS-fluorescence dual modal nanoprobes (DMNPs) for detecting duplex co-expressed cancer markers. AuNPs with $40 \mathrm{~nm}$ of diameter containing Raman reporter molecules adsorbed onto their surface were synthesized and encapsulated with $20 \mathrm{~nm}$ silica shells. Then, a fluorescent layer was covalently attached onto their surface, followed by a final outer silica shell and antibodies conjugation. The dual cancer marker detection was only possible thanks to the fabrication of 
different types of DMNPs (for the two cancer markers to detect different Raman reporters, fluorophores and antibodies were used). A similar approach was demonstrated for detecting three serological cancer markers using a multiplex SERS-based assay (Li et al. 2015), where AuNSs containing a Raman reporter and a silica layer were conjugated to the antibodies. For each biomarker to be detected, a line on the SERS assay chip was immobilized with the respective antibody, allowing the multiplex SERS detection. For instance, the limit of detection (LOD) found for the three cancer markers is significantly smaller than the values reported with conventional methods.

The concept of trapping Raman reporters between gold cores and gold shells instead of gold cores and silica shells has been presented for in vivo sensing (Gandra et al. 2016). The SERS nanoprobe had a tunable gap between the core and the shell made of $20 \mathrm{~nm}$ AuNPs covered with $15 \mathrm{~nm}$ silver shell (porous $\mathrm{Au} / \mathrm{Ag}$ nanocage where the Raman reporter molecules are trapped on) and a subsequent gold shell (5-15 $\mathrm{nm}$ of thickness) on the top of the nanocage. A schematic illustration of the design of this core-shell SERS nanoprobe is shown in Fig. 14a. In vitro and in vivo stability tests were performed with breast epithelial cells. The stability was monitored from 5 to 24 h, as displayed in Fig. 14b.

\section{A PERSPECTIVE IN SERS (BIO)SENSING}

The concept of dual modal SERS-fluorescence nanoprobes (Lee et al. 2012) can be improved with the emerging analytical technique dual-mode shell-isolated nanoparticle enhanced Raman scattering - shell-isolated nanoparticle enhanced fluorescence (SHINERS-SHINEF) (Fang et al. 2015, Li et al. 2017). SHINERS (Li et al. 2010) and SHINEF (Guerrero and Aroca 2011) are plasmon-enhanced spectroscopy phenomena based on plasmonic metallic nanostructures (most commonly silver and gold) coated with silica, called SHINs (shell-isolated nanoparticles) (Li et al. 2010, 2013). It is known that a continuous transition from fluorescence enhancement to fluorescence quenching is observed by varying the molecule-nanoparticle distance. The optimum molecule-nanoparticle separation to achieve enhanced fluorescence is reached by using spacers (Gersten and Nitzan 1981). Since the distance between a molecule and the nanostructure can be easily controlled by tuning the silica shell thickness, SHINs are ideal to promote SHINERS and/or SHINEF (Li et al. 2010, Guerrero and Aroca 2011). Their advantages include: i) silica shell thickness control, with a nanometer precision ( $\mathrm{Li}$ et al. 2013), preventing the quenching effect and enhancing the fluorescence signal; ii) good dispersity of the SHINs in organic solvents and water for applications in solution; iii) the silica shell protects the metal core from chemical reactivity with the analytes, which can reduce the potential cytotoxicity of metal nanoparticles for applications in living cells ( $\mathrm{Li}$ et al. 2017). For instance, the dual-mode SHINERS-SHINEF was first used to confirm that scattering scales as the fourth power of the local field enhancement while the fluorescence is proportional to the square of the local field enhancement (Guerrero et al. 2012). The latter was proven by collecting SHINERS and SHINEF spectra from the same molecular system (crystal violet solution, excited with laser line at $514.5 \mathrm{~nm}$ ), as displayed in Fig. 15. Therefore, the dual-mode SHINERS-SHINEF ( $\mathrm{Li}$ et al. 2017) is a promising tool with potential applications in improving the performance of (bio)sensing platforms and nanoprobes.

\section{CONCLUSIONS}

There are various ways through which plasmonic phenomena can be exploited for sensing and biosensing, and in this paper we have tried to cover some of the most promising possibilities. The control of size and 

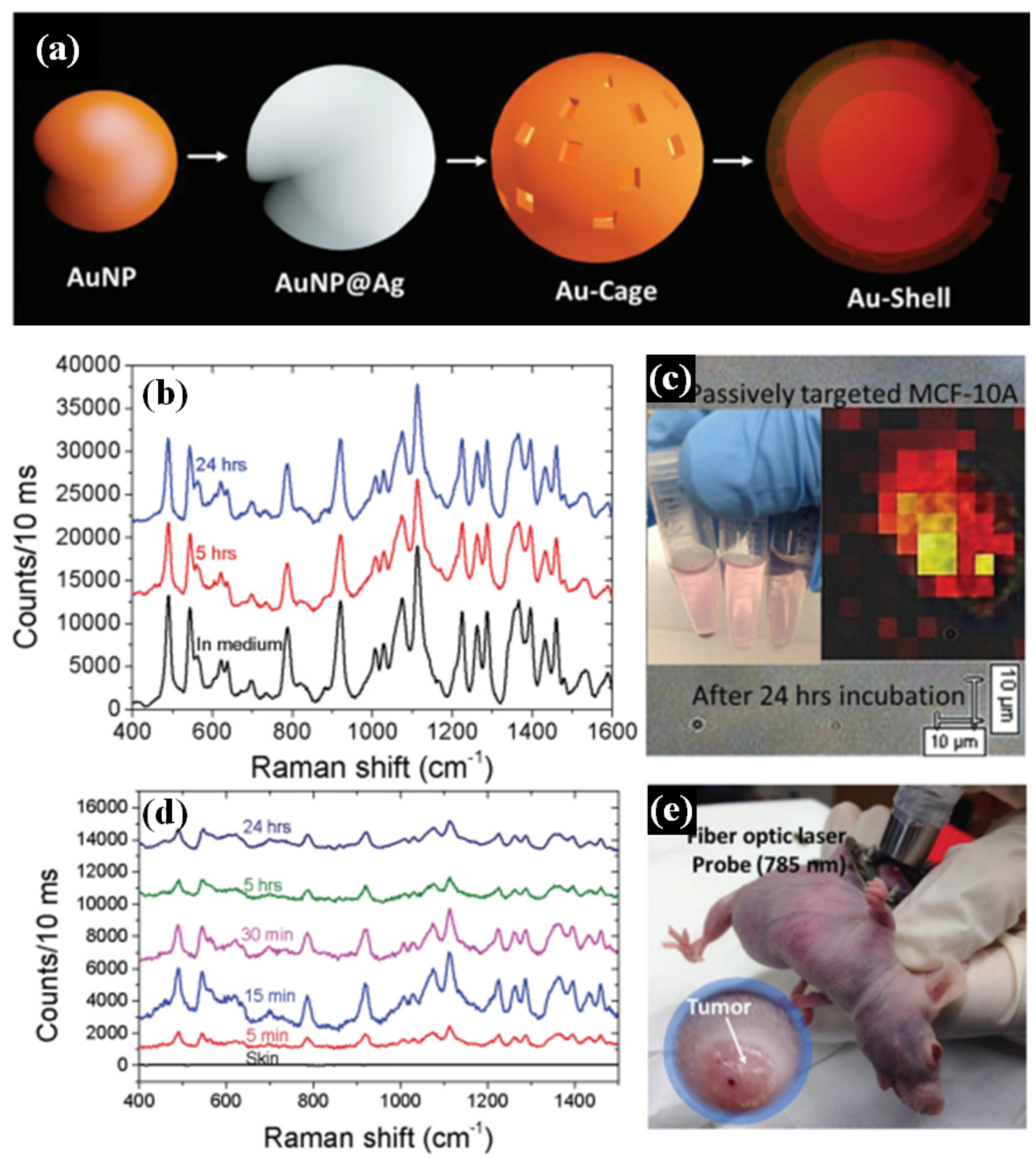

Figure 14 - (a) Schematic illustration of the design and synthesis of core-shell SERS nanoprobe with a gap of $10 \mathrm{~nm}$. (b) In vitro stability of SERS nanoprobes targeting breast epithelial cells (MCF 10A), from 5 to $24 \mathrm{~h}$ of incubation. (c) In vitro SERS mapping of nanoprobes at single cell level to confirm internalization after targeting. (d) In vivo SERS stability of the same nanoprobes in immune-compromised mouse with tumor located in the window chamber. The nanoprobes were injected directly into the tumor and the SERS signal was followed over time. SERS nanoprobe signal is detectable even after $24 \mathrm{~h}$, which indicates these probes are not susceptible to tissue response and tumorigenic enzymes. (e) Immune-compromised mouse with tumor located in the window chamber. The SERS signal was collected at the tumor location using an optical fiber. Reproduced with permission (Gandra et al. 2016). Copyright 2016, Royal Society of Chemistry. 


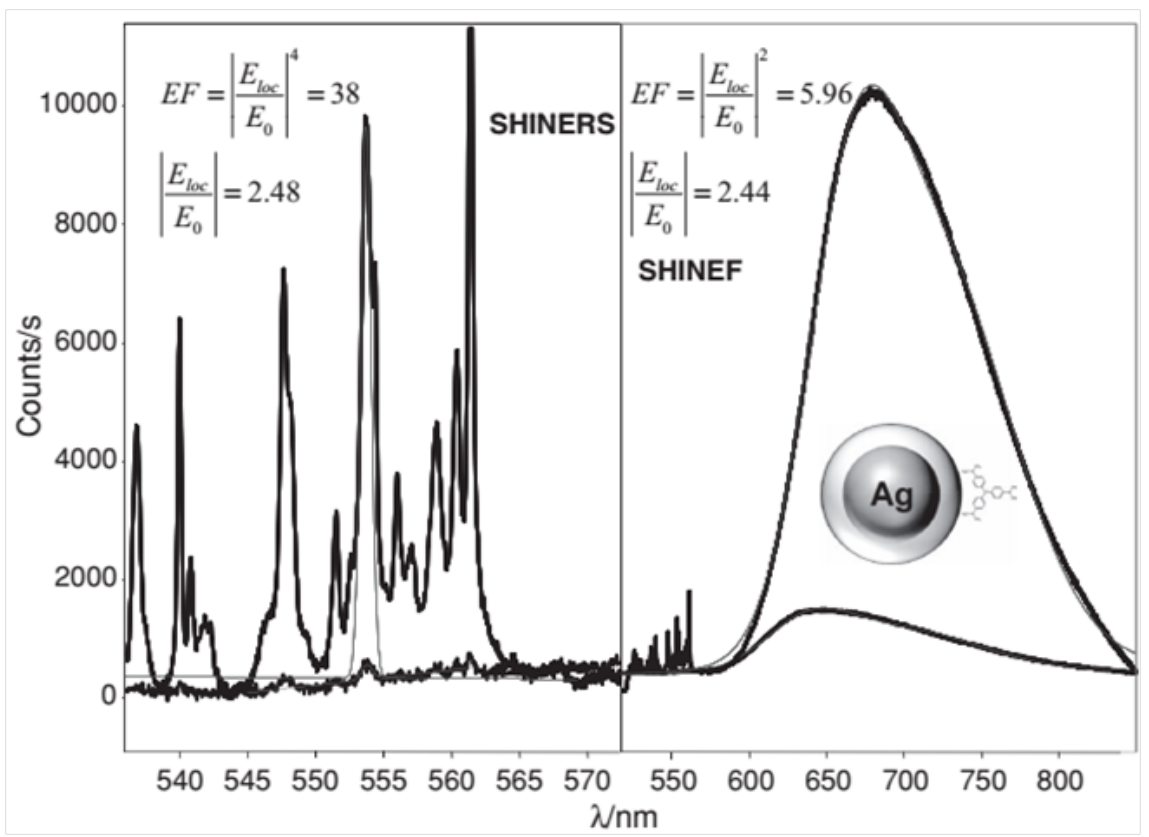

Figure 15 - SHINERS+SHINEF spectra of crystal violet in solution proving the known $\mathrm{E}^{2} / \mathrm{E}^{4}$ relationship for SHINEF/SHINERS enhancement factors. Laser line at $514.5 \mathrm{~nm}$. Reproduced with permission.(Guerrero et al. 2012) Copyright 2012, Wiley.

shape of nanostructures as well as of nanostructured surfaces, which can also be functionalized, has made it possible to enhance SPR sensing and SERS-based sensing. Emphasis here was placed on novel materials, such as magnetic nanoparticles and metamaterials, which have been used for generating the plasmonic enhancement of electromagnetic field, in conjugation with detection techiques. With regard to SERS with plasmonic nanostructures, recent developments were highlighted in detecting and/or monitoring trace levels of chemical and biological analytes. Special attention was given to the design of plasmon-enhanced nanostructures with different architectures and materials, providing potential applications in SERS (bio)sensing and nanoprobes.

\section{ACKNOWLEDGMENTS}

The authors acknowledge the financial support from the Conselho Nacional de Desenvolvimento Científico e Tecnológico (CNPq) and Fundação de Amparo à Pesquisa do Estado de São Paulo (FAPESP) (2013/14262-7, 2013/01897-4 and 2016/12311-9).

\section{REFERENCES}

ABBAS A, LINMAN MJ AND CHENG Q. 2011. New trends in instrumental design for surface plasmon resonance-based biosensors. Biosens Bioelectron 26: 1815-1824.

AGUILAR-ARTEAGA K, RODRIGUEZ JA AND BARRADO E. 2010. Magnetic solids in analytical chemistry: a review. Anal Chim Acta 674: 157-165.

AKIN MS, YILMAZ M, BABUR E, OZDEMIR B, ERDOGAN H, TAMER U AND DEMIREL G. 2014. Large area uniform deposition of silver nanoparticles through bio-inspired polydopamine coating on silicon nanowire arrays for practical SERS applications. J Mater Chem B 2: 4894-4900.

AMBASHTA RD AND SILLANPAA M. 2010. Water purification using magnetic assistance: a review. J Hazardo Mater $180: 38-49$. 
ANKER JN, HALL WP, LYANDRES O, SHAH NC, ZHAO J AND VAN DUYNE RP. 2008. Nat Mat 7: $442-453$.

ARMISTEAD PM AND THORP HH. 2000. Modification of indium tin oxide electrodes with nucleic acids: detection of attomole quantities of immobilized DNA by electrocatalysis. Anal Chem 72: 3764-3770.

AROCA R. 2007. Surface-Enhanced Vibrational Spectroscopy, Wiley, 260 p.

ATTA S, TSOULOS TV AND FABRIS L. 2016. Shaping Gold Nanostar Electric Fields for Surface-Enhanced Raman Spectroscopy Enhancement via Silica Coating and Selective Etching. J Phys Chem C 120: 20749-20758.

BANTZ KC, MEYER AF, WITTENBERG NJ, IM H, KURTULUŞ Ö, LEE SH, LINDQUIST NC, OH SH AND HAYNES CL. 2011. Recent Progress in SERS Biosensing. Phys Chem Chem Phys 13: 11551-11567.

BEVERIDGE JS, STEPHENS JR AND WILLIAMS ME. 2011. The use of magnetic nanoparticles in analytical chemistry. Annu Rev Anal Chem 4: 251-273.

BIBIKOVA O, HAAS J, LÓPEZ-LORENTE AI, POPOV A, KINNUNEN M, MEGLINSKI I AND MIZAIKOFF B. 2017. Towards enhanced optical sensor performance: SEIRA and SERS with plasmonic nanostars. Analyst 142: 951-958.

BRULS DM ET AL. 2009. Rapid integrated biosensor for multiplexed immunoassays based on actuated magnetic nanoparticles. Lab Chip 9: 3504-3510.

CABALLERO B, GARCÍA-MARTÍN A AND CUEVAS JC. 2016. Hybrid Magnetoplasmonic Crystals Boost the Performance of Nanohole Arrays as Plasmonic Sensors. ACS Phot 3: 203-208.

CANNON B, CAMPOS AR, LEWITZ Z, WILLETS KA AND RUSSELL R. 2012. Zeptomole detection of DNA nanoparticles by single-molecule fluorescence with magnetic field-directed localization. Anal Biochem 431: 40-47.

CAO C, ZHANG J, WEN X, DODSON S. L, DAO NT, WONG LM, WANG S, LI S, PHAN AT AND XIONG Q. 2013. Metamaterials-Based Label-Free Nanosensor for Conformation and Affinity Biosensing. ACS Nano 7: 7583-7591.

CARIDAD JM, WINTERS S, MCCLOSKEY D, DUESBERG GS, DONEGAN JF AND KRSTIĆ V. 2017. Hot-Volumes as Uniform and Reproducible SERS-Detection Enhancers in Weakly-Coupled Metallic Nanohelices. Sci Rep 7: 45548.

CARREGAL-ROMERO S, CABALLERO-DÍAZ E, BEQA L, ABDELMONEM AM, OCHS M, HÜHN D, SUAU BS, VALCARCEL M AND PARAK WJ. 2013. Muliplexed sensing and imaging with colloidal nano- and microparticles. Annu Rev Anal Chem 6: 53-81.

CHATTERJEE S, RINGANE AB, ARYA A, DAS GM, DANTHAM VR, LAHA R AND HUSSIAN S. 2016. A high-yield, one-step synthesis of surfactant-free gold nanostars and numerical study for single-molecule SERS application. J Nanoparticle Res 18 : 242.

CHEN HY, LIN MH, WANG CY, CHANG YM AND GWO S. 2015. Large-Scale Hot Spot Engineering for Quantitative SERS at the Single-Molecule Scale. J Am Chem Soc 137: 13698-13705.

CHEN L, WANG T AND TONG J. 2011. Application of derivatized magnetic materials to the separation and the preconcentration of pollutants in water samples. Trend Anal Chem 30: 1095-1108.

CHEN T, WANG H, CHEN G, WANG Y, FENG Y, TEO WS, WU T AND CHEN H. 2010. Hotspot-induced transformation of surface-enhanced Raman scattering fingerprints. ACS Nano 4: 3087-3094.

CHOU KH, LIN EP, CHEN TC, LAI CH, WANG LW, CHANG KW, LEE GB AND LEE MC. 2014. Application of strong transverse magneto-optical Kerr effect on high sensitive surface plasmon grating sensors. Opt Exp 22: 19794-19802.

CIOU SH, CAO YW, HUANG HC, SU DY AND HUANG CL. 2009. SERS enhancement factors studies of silver nanoprism and spherical nanoparticle colloids in the presence of bromide ions. J Phys Chem C 113: 9520-9525.

COLOMBO M, CARREGAL-ROMERO S, CASULA MF, GUTIÉRREZ L, MORALES MP, BÖHM IB, HEVERHAGEN JT, PROSPERI D AND PARAK WJ. 2012. Biological applications of magnetic nanoparticles. Chem Soc Rev 12: $4306-4334$.

DAGHESTANI HN AND DAY BW. 2010. Theory and Applications of Surface Plasmon Resonance, Resonant Mirror, Resonant Waveguide Grating, and Dual Polarization Interferometry Biosensors. Sensors 10: 9630-9646.

DECKERT F AND LEGAY F. 1999. Development and validation of an immunoreceptor assay for simulect based on surface plasmon resonance. Anal Biochem 274: 81-89.

ELEFTHERIADES GV, IYER AK AND KREMER PC. 2002. Planar negative refractive index media using periodically L-C loaded transmission lines. IEEE Trans Microwave Theory Tech 50: 2702-2712.

FANG PP, LU X, LIU H AND TONG Y. 2015. Applications of shell-isolated nanoparticles in surface-enhanced Raman spectroscopy and fluorescence. TrAC Trends Anal Chem 66: 103-117.

FANG Y, SEONG NH AND DLOTT DD. 2008. Measurement of the Distribution of Site Enhancements in Surface-Enhanced Raman Scattering. Science 321: 388-392.

FENG S AND HALTERMAN K. 2012. Coherent perfect absorption in epsilon-near-zero metamaterials. Phys Rev B 86: 165103.

FORTUNI B, FUJITA Y, RICCI M, INOSE T, AUBERT R, LU G, HUTCHISON JA, HOFKENS J, LATTERINI L AND UJI-I H. 2017. A novel method for in situ synthesis of SERS-active gold nanostars on polydimethylsiloxane film. Chem Commun 53: 
5121-5124.

GANDRA N, HENDARGO HC, NORTON SJ, FALES AM, PALMER GM AND VO-DINH T. 2016. Tunable and amplified Raman gold nanoprobes for effective tracking (TARGET): in vivo sensing and imaging. Nanoscale 8: 8486-8494.

GARDNER T, FRISBIE C AND WRIGHTON M. 1995. Systems for orthogonal self-assembly of electroactive monolayers on Au and ITO: an approach to molecular electronics. J Am Chem Soc 117: 6927-6933.

GERSTEN J AND NITZAN A. 1981. Spectroscopic properties of molecules interacting with small dielectric particles. J Chem Phys 75: 1139-1152.

GESTWICKI JE, HSIEH HV AND PITNER JB. 2001. Using Receptor Conformational Change To Detect Low Molecular Weight Analytes by Surface Plasmon Resonance. Anal Chem 73: 5732-5737.

GONG B, ZHAO X, PAN Z, LI S, WANG X, ZHAO Y AND LUO C. 2014. A visible metamaterial fabricated by self-assembly method. Sci Rep 4: 4713.

GOODMAN AM, CAO Y, URBAN C, NEUMANN O, AYALA-OROZCO C, KNIGHT MW, JOSHI A, NORDLANDER P AND HALAS NJ. 2014. The Surprising in Vivo Instability of Near-IR-Absorbing Hollow Au-Ag Nanoshells. ACS Nano 8: $3222-3231$.

GREENELTCH NG, BLABER MG, HENRY AI, SCHATZ GC AND VAN DUYNE RP. 2013. Immobilized nanorod assemblies: Fabrication and understanding of large area surface-enhanced Raman spectroscopy substrates. Anal Chem 85: $2297-2303$.

GRUNIN AA, MUKHA IR, CHETVERTUKIN AV AND FEDYANIN AA. 2016. Refractive index sensor based on magnetoplasmonic crystals. J Magn Magn Mat 415: 72-76.

GUERRERO AR AND AROCA RF. 2011. Surface-Enhanced Fluorescence with Shell-Isolated Nanoparticles (SHINEF). Angew Chem Int Ed 50: 665-668.

GUERRERO AR, ZHANG Y AND AROCA RF. 2012. Experimental Confirmation of Local Field Enhancement Determining FarField Measurements with Shell-Isolated Silver Nanoparticles. Small 8: 2964-2967.

HAES AJ AND VAN DUYNE RP. 2002. A nanoscale optical biosensor: Sensitivity and selectivity of an approach based on the localized surface plasmon resonance spectroscopy of triangular silver nanoparticles. J Am Chem Soc 124: 10596-10604.

HAO F, NEHL CL, HAFNER JH AND NORDLANDER P. 2007. Plasmon resonances of a gold nanostar. Nano Lett 7: 729-732.

HATAB NA, HSUEH CH, GADDIS AL, RETTERER ST, LI JH, ERES G, ZHANG Z AND GU B. 2010. Free-Standing Optical Gold Bowtie Nanoantenna with Variable Gap Size for Enhanced Raman Spectroscopy. Nano Lett 10: 4952-4955.

HENRY AI, SHARMA B, CARDINAL MF, KUROUSKI D AND VAN DUYNE RP. 2016. Surface-Enhanced Raman Spectroscopy Biosensing: In Vivo Diagnostics and Multimodal Imaging. Anal Chem 88: 6638-6647.

HOMOLA J. 2008. Surface Plasmon Resonance Sensors for Detection of Chemical and Biological Species. Chem Rev 108: $462-493$.

HU W, CHEN SJ, HUANG KT, HSU J, CHEN W, CHANG G AND LAI KA. 2004. A Novel Ultrahigh-Resolution Surface Plasmon Resonance Biosensor with an Au Nanocluster-Embedded Dielectric Film. Biosens Bioelectron 19: 1465-1471.

HUANG JA, ZHAO YQ, ZHANG XJ, HE LF, WONG TL, CHUI YS, ZHANG WJ AND LEE ST. 2013. Ordered Ag/Si Nanowires Array: Wide-Range Surface-Enhanced Raman Spectroscopy for Reproducible Biomolecule Detection. Nano Lett 13: 50395045 .

HUANG SH AND JUANG RS. 2011. Biochemical and biomedical applications of multifunctional magnetic nanoparticles: a review. J Nanopart Res 13: 4411-4430.

IGNATYEVA DO, KNYAZEV GA, KAPRALOV PO, DIETLER G, SEKATSKII SK AND BELOTELOV VI. 2016. Magnetooptical plasmonic heterostructure with ultranarrow resonance for sensing applications. Sci Rep 6: 28007.

IRANIFAM M. 2013. Analytical applications of chemiluminescence-detection systems assisted by magnetic microparticles and nanoparticles. Trend Anal Chem 51: 51-70.

IWASAKI Y, HORIUCHI T AND NIWA O. 2001. Detection of Electrochemical Enzymatic Reactions by Surface Plasmon Resonance Measurement. Anal Chem 73: 1595-1598.

KABASHIN AV, EVANS P, PASTKOVSKY S, HENDREN W, WURTZ GA, ATKINSON R, POLLARD R, PODOLSKIY VA AND ZAYATS AV. 2009. Plasmonic nanorod metamaterials for biosensing. Nat Mat 8: 867.

KARLSSON R. 2004. SPR for Molecular Interaction Analysis: A Review of Emerging Application Areas. J Mol Recognit 17: 151-161.

KNEIPP K, MOSKOVITS M AND KNEIPP H. 2006. Surface-enhanced Raman scattering physics and applications, Topics Appl Phys, p. 105-123.

KNEIPP K, WANG Y, KNEIPP H, PERELMAN LT, ITZKAN I, DASARI RR AND FELD MS. 1997. Single molecule detection using surface-enhanced Raman scattering (SERS). Phys Rev Lett 78: 1667-1670.

KOIDE S, IWASAKI Y, HORIUCHI T, NIWA O, TAMIYA E AND YOKOYAMA K. 2000. A novel biosensor using electrochemical surface plasmon resonance measurements. Chem Comm 741-742. 
KRAVETS VG ET AL. 2013. Singular phase nano-optics in plasmonic metamaterials for label-free single-molecule detection. Nat Mat 12: 304.

KRETSCHMANN E AND RAETHER H. 1968. Radiative decay of non radiative surface plasmons excited by light. Z Naturforsch 23a: 2135-2136.

KUMAR J, THOMAS R, SWATHI RS AND THOMAS KG. 2014. Au nanorod quartets and Raman signal enhancement: towards the design of plasmonic platforms. Nanoscale 6: 10454-10459.

KUMAR P, KHOSLA R, SONI M, DEVA D AND SHARMA SK. 2017. A highly sensitive, flexible SERS sensor for malachite green detection based on Ag decorated microstructured PDMS substrate fabricated from Taro leaf as template. Sensors Actuators B Chem 246: 477-486.

LE BEULZE A ET AL. 2017. Robust raspberry-like metallo-dielectric nanoclusters of critical sizes as SERS substrates. Nanoscale 9: $5725-5736$.

LEE S, CHON H, YOON SY, LEE EK, CHANG SI, LIM DW AND CHOO J. 2012. Fabrication of SERS-fluorescence dual modal nanoprobes and application to multiplex cancer cell imaging. Nanoscale 4: 124-129.

LEE S, KANG B, KEUM H, AHMED N, ROGERS JA, FERREIRA PM, KIM S AND MIN B. 2016. Heterogeneously Assembled Metamaterials and Metadevices via 3D Modular Transfer Printing. Sci Rep 6: 27621.

LE RU E AND ETCHEGOIN P. 2009. Principles of Surface-Enhanced Raman Spectroscopy, Elsevier Science, 688 p.

LE RU EC, GRAND J, SOW I, SOMERVILLE WRC, ETCHEGOIN PG, TREGUER-DELAPIERRE M, CHARRON G, FÉLIDJ N, LÉVI G AND AUBARD J. 2011. A Scheme for Detecting Every Single Target Molecule with Surface-Enhanced Raman Spectroscopy. Nano Lett 11: 5013-5019.

LI JF ET AL. 2010. Shell-isolated nanoparticle-enhanced Raman spectroscopy. Nature 464: 392-395.

LI JF ET AL. 2013. Surface analysis using shell-isolated nanoparticle-enhanced Raman spectroscopy. Nat Protoc 8: 52-65.

LI JF, LI CY AND AROCA RF. 2017. Plasmon-enhanced fluorescence spectroscopy. Chem Soc Rev 46: 3962-3979.

LI M, KANG JW, SUKUMAR S, DASARI RR AND BARMAN I. 2015. Multiplexed detection of serological cancer markers with plasmon-enhanced Raman spectro-immunoassay. Chem Sci 6: 3906-3914.

LI XS, ZHU GT, LUO YB, YUAN BF AND FENG YQ. 2013. Synthesis and applications of functionalized magnetic materials in sample preparation. Trend Anal Chem 45: 233-247.

LI Z, YU Y, CHEN Z, LIU T, ZHOU ZK, HAN JB, LI J, JIN C AND WANG X. 2013. Ultrafast third-order optical nonlinearity in $\mathrm{Au}$ triangular nanoprism with strong dipole and quadrupole plasmon resonance. J Phys Chem C 117: 20127-20132.

LIANG RP, YAO GH, FAN LX AND QIU JD. 2012. Magnetic $\mathrm{Fe}_{3} \mathrm{O}_{4} @ \mathrm{Au}$ composite-enhanced surface plasmon resonance for ultrasensitive detection of magnetic nanoparticle-enriched $\alpha$-fetoprotein. Anal Chim Acta 737: 22-28.

LIEDBERG B, NYLANDER C AND LUNSTRÖM I. 1983. Surface plasmon resonance for gas detection and biosensing. Sens Act 4: 299-304.

LIU N, WEISS T, MESCH M, LANGGUTH L, EIGENTHALER U, HIRSCHER M, SÖNNICHSEN C AND GIESSEN H. 2010. Planar Metamaterial Analogue of Electromagnetically Induced Transparency for Plasmonic Sensing. Nano Lett 10: 1103-1107.

LÖFÅS S, MALMQVIST M, RÖNNBERG I, STENBERG E, LIEDBERG B AND LUNSTRÖM I. 1991. Bioanalysis with Surface Plasmon Resonance. Sens Act B Chem 5: 79-84.

MACCAFERRI N, GREGORCZYK KE, DE OLIVEIRA TV, KATAJA M, VAN DIJKEN S, PIRZADEH Z, DMITRIEV A, ÅKERMAN J, KNEZ M AND VAVASSORI P. 2015. Ultrasensitive and label-free molecular-level detection enabled by light phase control in magnetoplasmonic nanoantennas. Nat Comm 6: 6150.

MAIER SA. 2007. Plasmonics: Fundamentals and Applications, Springer US, 224 p.

MANERA MG ET AL. 2011. Enhanced gas sensing performance of $\mathrm{TiO}_{2}$ functionalized magneto-optical SPR sensors. J Mater Chem 21: 16049-16056.

MANERA MG, COLOMBELLI A, RELLA R, CARICATO A, COZZOLI PD, MARTINO M AND VASANELLI L. 2012. TiO 2 brookite nanostructured thin layer on magneto-optical surface plasmon resonance transductor for gas sensing applications. $\mathrm{J}$ Appl Phys 112: 053524.

MANERA MG, FERREIRO-VILA E, GARCIA-MARTIN JM, GARCIA-MARTIN A AND RELLA R. 2014. Enhanced antibody recognition with a magneto-optic surface plasmon resonance (MO-SPR) sensor. Bios Bioelect 58: 114-120.

MANI V, CHIKKAVEERAIAH BV AND RUSLING JF. 2011. Magnetic particles in ultrasensitive biomarker protein measurements for cancer detection and monitoring. Expert. Opin Med Diagn 5: 381-391.

MAO Y, BAO Y, WANG W, LI Z, LI F AND NIU L. 2011. Layer-by-Layer Assembled Multilayer of graphene/Prussian Blue toward Simultaneous Electrochemical and SPR Detection of $\mathrm{H}_{2} \mathrm{O}_{2}$. Talanta 85: 2106-2112.

MARKOVICH I AND MANDLER D. 2001. Preparation and characterization of octadecylsilane monolayers on indium-tin oxide (ITO) surfaces. J Electroanal Chem 500: 453-460. 
MCLELLAN JM, LI ZY, SIEKKINEN AR AND XIA Y. 2007. The SERS Activity of a Supported Ag Nanocube Strongly Depends on Its Orientation Relative to Laser Polarization. Nano Lett 7: 1013-1017.

MÉTRAUX GS AND MIRKIN CA. 2005. Rapid thermal synthesis of silver nanoprisms with chemically tailorable thickness. Adv Mater 17: 412-415.

MICHAELS AM, JIANG AND BRUS L. 2000. Ag Nanocrystal Junctions as the Site for Surface-Enhanced Raman Scattering of Single Rhodamine 6G Molecules. J Phys Chem B 104: 11965-11971.

MOLINER-MARTINEZ Y, RIBERA A, CORONADO E AND CAMPÍNS-FALCÓ P. 2011. Preconcentration of emerging contaminants in environmental water samples by using silica supported Fe3O4 magnetic nanoparticles for improving mass detection in capillary liquid chromatography. J Chromatogr A 1218: 2276-2283.

MOSKOVITS M. 1978. Surface roughness and the enhanced intensity of Raman scattering by molecules adsorbed on metals. J Chem Phys 69: 4159-4161.

NGUYEN HH, PARK J, KANG S AND KIM M. 2015. Surface Plasmon Resonance: A Versatile Technique for Biosensor Applications. Sensors 15: 10481-10510.

NIE S AND EMORY SR. 1997. Probing Single Molecules and Single Nanoparticles by Surface-Enhanced Raman Scattering. Science 275: 1102-1106.

NIU W, DUAN Y, QING Z, HUANG H AND LU X. 2017. Shaping Gold Nanocrystals in Dimethyl Sulfoxide: Toward Trapezohedral and Bipyramidal Nanocrystals Enclosed by $\{311\}$ Facets. J Am Chem Soc 139: 5817-5826.

NYLANDER C, LIEDBERG B AND LIND T. 1982. Gas Detection by Means of Surface Plasmon Resonance. 3: 79-88.

OH JK AND PARK JM. 2011. Iron oxide-based superparamagnetic polymeric nanomaterials: design, preparation, and biomedical application. Progr Polym Sci 36: 168-189.

OH S, YUN Y, KIM D AND HAN S. 1999. Formation of a Self-Assembled Monolayer of Diaminododecane and a Heteropolyacid Monolayer on the ITO Surface. Langmuir 15: 4690-4692.

OH YJ AND JEONG KH. 2012. Glass Nanopillar Arrays with Nanogap-Rich Silver Nanoislands for Highly Intense Surface Enhanced Raman Scattering. Adv Mater 24: 2234-2237.

OLIVEIRA MJ, QUARESMA P, DE ALMEIDA MP, ARAÚJO A, PEREIRA E, FORTUNATO E, MARTINS R, FRANCO R AND ÁGUAS H. 2017. Office paper decorated with silver nanostars - an alternative cost effective platform for trace analyte detection by SERS. Sci Rep 7: 2480.

PARK J, KANG JH, LIU X AND BRONGERSMA ML. 2015. Electrically Tunable Epsilon-Near-Zero (ENZ) Metafilm Absorbers. Sci Rep 5: 15754.

PASQUALE AJ, REINHARD BM AND DAL NEGRO L. 2011. Engineering Photonic-Plasmonic Coupling in Metal Nanoparticle Necklaces. ACS Nano 5: 6578-6585.

PENDRY JB, HOLDEN AJ, ROBBINS DJ AND STEWART WJ. 1999. Magnetism from conductors and enhanced nonlinear phenomena. IEEE Trans Microwave Theory Tech 47: 2075-2084.

PILIARIK M, VAISOCHEROVÁ H AND HOMOLA J. 2009. Surface plasmon resonance biosensing. Methods Mol Biol 503: 65-88.

PODDUBNY A, IORSH I, BELOV P AND KIVSHAR Y. 2013. Hyperbolic Metamaterials. Nat Phot 7: 958.

QIAN Z, HASTINGS SP, LI C, EDWARD B, MCGINN CK, ENGHETA N, FAKHRAAI Z AND PARK SJ. 2015. Raspberry-like Metamolecules Exhibiting Strong Magnetic Resonances. ACS Nano 9: 1263-1270.

REGATOS D, FARIÑA D, CALLE A, CEBOLLADA A, SEPÚLVEDA B, ARMELLES G AND LECHUGA LM. 2010. Au/Fe/Au multilayer transducers for magneto-optic surface plasmon resonance sensing. J Appl Phys 108: 054502.

REGATOS D, SEPÚLVEDA B, FARIÑA D, CARRASCOSA LG, LECHUGA LM. 2011. Suitable combination of noble/ferromagnetic metal multilayers for enhanced magneto-plasmonic biosensing. Opt Exp 19: 8336-8346.

RODRÍGUEZ-LORENZO L, ÁLVAREZ-PUEBLA R, PASTORIZA-SANTOS I, MAZZUCCO S, STÉPHAN O, KOCIAK M, LIZ-MARZÁN L, GARCÍA DE ABAJO J. 2009. Zeptomol detection through controlled ultrasensitive surface-enhanced Raman scattering. J Am Chem Soc 131: 4616-4618.

ROMO-HERRERA JM, ALVAREZ-PUEBLA RA AND LM LIZ-MARZÁN. 2011. Controlled assembly of plasmonic colloidal nanoparticle clusters. Nanoscale 3: 1304-1315.

SCARABELLI L, CORONADO-PUCHAU M, GINER-CASARES JJ, LANGER J AND LIZ-MARZÁN LM. 2014. Monodisperse gold nanotriangles: Size control, large-scale self-assembly, and performance in surface-enhanced Raman scattering. ACS Nano 8: 5833-5842.

SEPÚLVEDA B, CALLE A, LECHUGA AM, ARMELLES G. 2006. Highly sensitive detection of biomolecules with the magnetooptic surface plasmon resonance sensor. Opt Lett 31: 1085-1087. 
SEUNG JL, JEONG MB AND MOSKOVITS M. 2008. Polarization-dependent surface-enhanced Raman scattering from a silvernanoparticle-decorated single silver nanowire. Nano Lett 8: 3244-3247.

SHANKARAN DR, GOBI KV AND MIURA N. 2007. Recent Advancements in Surface Plasmon Resonance Immunosensors for Detection of Small Molecules of Biomedical, Food and Environmental Interest. Sens Act B Chem 121: 158-177.

SHELBY RA, SMITH DR AND SCHULTZ S. 2001. Experimental Verification of a Negative Index of Refraction. Science 292: 77-79.

SHEN Y, ZHOU J, LIU T, TAO Y, JIANG R, LIU M, XIAO G, ZHU J, ZHOU ZK, WANG X, JIN C AND WANG J. 2013. Plasmonic gold mushroom arrays with refractive index sensing figures of merit approaching the theoretical limit. Nat Comm 4: 2381.

SHERRY LJ, JIN R, MIRKIN CA, SCHATZ GC AND VAN DUYNE RP. 2006. Localized Surface Plasmon Resonance Spectroscopy of Single Silver Triangular Nanoprisms. Nano Lett 6: 2060-2065.

SHIOHARA A, LANGER J, POLAVARAPU L AND LIZ-MARZÁN LM. 2014. Solution processed polydimethylsiloxane/gold nanostar flexible substrates for plasmonic sensing. Nanoscale 6: 9817-9823.

SINGH JP, CHU H, ABELL J, TRIPP RA AND ZHAO Y. 2012. Flexible and mechanical strain resistant large area SERS active substrates. Nanoscale 4: 3410-3414.

SIVAPALAN ST, DEVETTER BM, YANG TK, VAN DIJK T, SCHULMERICH MV, CARNEY PS, BHARGAVA R AND MURPHY CJ. 2013. Off-resonance surface-enhanced raman spectroscopy from gold nanorod suspensions as a function of aspect ratio: Not what we thought. ACS Nano 7: 2099-2105.

SIVASHANMUGAN K, DER LIAO J, LIU BH, YAO CK AND LUO SC. 2015. Ag nanoclusters on ZnO nanodome array as hybrid SERS-active substrate for trace detection of malachite green. Sens Act B Chem 207: 430-436.

SMITH DR, PADILLA WJ, VIER DC, NEMAT-NASSER SC AND SCHULTZ S. 2000. Composite Medium with Simultaneously Negative Permeability and Permittivity. Phys Rev Lett 84: 4184-4187

SOELBERG SD, STEVENS RC, LIMAYE AP, FURLONG CE. 2009. Surface Plasmon Resonance Detection Using AntibodyLinked Magnetic Nanoparticles for Analyte Capture, Purification, Concentration, and Signal Amplification. Anal Chem 81: 2357-2363.

SONG C, YANG B, ZHU Y, YANG Y AND WANG L. 2017. Ultrasensitive sliver nanorods array SERS sensor for mercury ions. Biosens Bioelectron 87: 59-65.

SREEKANTH KV, ALAPAN Y, ELKABBASH M, ILKER E, HINCZEWSKI M, GURKAN UA, DE LUCA A AND STRANGI G. 2016. Extreme sensitivity biosensing platform based on hyperbolic metamaterials. Nat Mat 15: 621.

TANG SC AND LO IM. 2013. Magnetic nanoparticles: essential factors for sustainable environmental applications. Water Res 47: 2613-2632.

TIWARI VS, OLEG T, DARBHA GK, HARDY W, SINGH JP AND RAY PC. 2007. Non-resonance SERS effects of silver colloids with different shapes. Chem Phys Lett 446: 77-82.

TRAVISS D, BRUCK R, MILLS B, ABB M AND MUSKENS OL. 2013. Ultrafast plasmonics using transparent conductive oxide hybrids in the epsilon-near-zero regime. Appl Phys Lett 102: 121112.

TSENG P, DI CARLO D AND JUDY JW. 2009. Rapid and Dynamic Intracellular Patterning of Cell-Internalized Magnetic Fluorescent Nanoparticles. Nano Lett 9: 3053-3059.

VALENTINE J, ZHANG S, ZENTGRAF T, ULIN-AVILA E, GENOV DA, BARTAL G AND ZHANG X. 2008. Three-dimensional optical metamaterial with a negative refractive index. Nature 455: 376.

VANDERKAM SK, GAWALT ES, SCHWARTZ J AND BOCARSLY AB. 1999. Electrochemically Active Surface Zirconium Complexes on Indium Tin Oxide. Langmuir 15: 6598-6600.

VASSANT S, ARCHAMBAULT A, MARQUIER F, PARDO F, GENNSER U, CAVANNA A, PELOUARD JL AND GREFFET JJ. 2012. Epsilon-near-zero mode for active optoelectronic devices. Phys Rev Lett 109: 237401.

VUTUKURU S, BETHI SR AND KANE RS. 2006. Protein Interactions with Self-Assembled Monolayers Presenting Multimodal Ligands: A Surface Plasmon Resonance Study. Langmuir 22: 10152-10156.

WANG C, RUAN W, JI N, JI W, LV S, ZHAO C AND ZHAO B. 2010. Preparation of Nanoscale Ag Semishell Array with Tunable Interparticle Distance and Its Application in Surface-Enhanced Raman Scattering. J Phys Chem C 114: 2886-2890.

WANG J, MUNIR A, ZHU Z AND ZHOU HS. 2010. Magnetic Nanoparticle Enhanced Surface Plasmon Resonance Sensing and Its Application for the Ultrasensitive Detection of Magnetic Nanoparticle-Enriched Small Molecules. Anal Chem 82: 6782-6789.

WANG J, WANG F, CHEN H, LIU X AND DONG S. 2008. Electrochemical surface plasmon resonance detection of enzymatic reaction in bilayer lipid membranes. Talanta 75: 666-670.

WANG Y, DOSTALEK J AND KNOLL W. 2011. Magnetic Nanoparticle-Enhanced Biosensor Based on Grating-Coupled Surface Plasmon Resonance. Anal Chem 83: 6202-6207. 
WEI H, REYES-CORONADO A, NORDLANDER P, AIZPURUA J AND XU H. 2010. Multipolar plasmon resonances in individual Ag nanorice. ACS Nano 4: 2649-2654.

WU C, KHANIKAEV AB, ADATO R, ARJU N, YANIK AA, ALTUG H AND SHVETS G. 2012. Fano-resonant asymmetric metamaterials for ultrasensitive spectroscopy and identification of molecular monolayers. Nat Mat 11: 69-75.

WU HJ, HENZIE J, LIN WC, RHODES C, LI Z, SARTOREL E, THORNER J, YANG P AND GROVES JT. 2012. Membraneprotein binding measured with solution-phase plasmonic nanocube sensors. Nat Methods 9: 1189-1191.

WU N, TIAN Y, ZOU X, SILVA V, CHERY A AND WANG X. 2012. High-efficiency optical ultrasound generation using one-pot synthesized polydimethylsiloxane-gold nanoparticle nanocomposite. J Opt Soc Am B 29: 2016-2020.

WU W ET AL. 2007. Optical metamaterials at near and mid-IR range fabricated by nanoimprint lithography. Appl Phys A 87: 143-150.

XU H, BJERNELD E, KÄLL M AND BÖRJESSON L. 1999. Spectroscopy of Single Hemoglobin Molecules by Surface Enhanced Raman Scattering. Phys Rev Lett 83: 4357-4360.

XU H, WANG XH, PERSSON MP, XU HQ, KÄLL M AND JOHANSSON P. 2004. Unified Treatment of Fluorescence and Raman Scattering Processes near Metal Surfaces. Phys Rev Lett 93: 243002.

XU L, ZONG C, ZHENG X, HU P, FENG J AND REN B. 2014. Label-free detection of native proteins by surface-enhanced Raman spectroscopy using iodide-modified nanoparticles. Anal Chem 86: 2238-2245.

XU Y AND WANG E. 2012. Electrochemical biosensors based on magnetic micro/ nanoparticles. Electrochim Acta 84: 62-73.

YAN C, ZHARNIKOV M, GÖLZHÄUSER A AND GRUNZE M. 2000. Preparation and Characterization of Self-Assembled Monolayers on Indium Tin Oxide. Langmuir 16: 6208-6215.

YANG L, LIU H, MA Y AND LIU J. 2012. Solvent-induced hot spot switch on silver nanorod enhanced Raman spectroscopy. Analyst 137: 1547-1549.

YOON J, ZHOU M, BADSHA MA, KIM TY, JUN YC AND HWANGBO CK. 2015. Broadband Epsilon-Near-Zero Perfect Absorption in the Near-Infrared. Sci Rep 5: 12788.

ZHANG Q, XU JJ, LIU Y AND CHEN HY. 2008. In-situ synthesis of poly(dimethylsiloxane)-gold nanoparticles composite films and its application in microfluidic systems. Lab Chip 8: 352-357.

ZHOU Q, HE Y, ABELL J, ZHANG Z AND ZHAO Y. 2011. Surface-enhanced Raman scattering from helical silver nanorod arrays. Chem Commun 47: 4466-4468. 